
\title{
25 Research Soure \\ Effects of Fibroblast Growth Factor 21 on Lactate Uptake and Usage in Mice with Diabetes-associated Cognitive Decline
}

Liangcai zhao ( $\sim$ zhaoliangcai@wmu.edu.cn )

Wenzhou Medical University https://orcid.org/0000-0001-5597-7407

Haowei Jiang

Wenzhou Medical University

Danjie Shen

Wenzhou Medical University

Qingqing Yi

Wenzhou Medical University

Jiaojiao Xie

Wenzhou Medical University

Jiapin Yan

Wenzhou Medical University

Chen Li

Wenzhou Medical University

Hong Zheng

Wenzhou Medical University

Hongchang Gao

Wenzhou Medical University

\section{Research Article}

Keywords: Diabetes mellitus, Fibroblast growth factor 21, Monocarboxylate transporter, Lactate, Learning and memory

Posted Date: February 1st, 2022

DOI: https://doi.org/10.21203/rs.3.rs-1301289/v1

License: (c) (1) This work is licensed under a Creative Commons Attribution 4.0 International License.

Read Full License 


\section{Abstract}

Fibroblast growth factor 21 (FGF21) is an endocrine hormone that exerts beneficial effects on glucose and lipid metabolic homeostasis. However, the impact of FGF21 on type 1 diabetes-associated cognitive decline (DACD) and its mechanisms of action remain unclear. In this study, we aimed to evaluate the effects of FGF21 on lactate uptake and usage in a mouse model of streptozotocin-induced DACD. Sixweek-old male C57BL/ 6 mice were divided into the control, diabetic, and FGF21 (which received $2 \mathrm{mg} / \mathrm{kg}$ recombinant human FGF21) groups. At the end of the treatment period, learning and memory performance, nuclear magnetic resonance-based metabonomics, and expressions of various hippocampal protein were analyzed to determine the efficacy of FGF21. The results showed that, compared to the control mice, the diabetic mice had reduced long-term memory performance after the hyperglycemic insult; decreased hippocampal levels of lactate dehydrogenase-B (LDH-B) activity, bioenergy metabolites, and monocarboxylate transporter 2 (MCT2); as well as increased lactate levels. Impaired phosphoinositide 3-kinase (PI3K) signaling was also observed in the diabetic mice. However, FGF21 treatment restored LDH-B activity, $\beta$-nicotinamide adenine dinucleotide, and ATP levels; increased MCT2 expression and PI3K signaling pathway, which in turn improved the learning and memory defects. These findings demonstrated that the effects of FGF21 in DACD were associated with its ability to improve LDH-B-mediated lactate usage and MCT2-dependent lactate uptake. Further, these beneficial effects of FGF21 in the hippocampus were mediated by the PI3K signaling pathways.

\section{Introduction}

Type 1 diabetes mellitus (T1D) is an autoimmune disease characterized by hyperglycemia and insulin deficiency due to pancreatic $\beta$-cell destruction. Notably, T1D is associated with cognitive impairment [1]. Diabetes-associated cognitive decline (DACD) is characterized by a decline in cognition, including learning and memory defects, as well as an impairment of language, understanding, and implementation, which seriously affect a patient's quality of life [2-4]. The pathogenesis of DACD is known to include oxidative stress, advanced glycation end products, and mitochondrial dysfunction $[5,6]$. Some metabolic disturbances (i.e., hyperglycemia), polyols, lipids, and glycation end products have also been implicated in cognitive impairment [7-12]. Considering the dramatic increase in the global number of patients with diabetes, research on potential therapeutic targets has gained great significance.

Fibroblast growth factor 21 (FGF21) is an endocrine hormone that functions as a regulator in insulin sensitivity as well as glucose and lipid metabolism [13]. Previous studies showed that the administration of FGF21 contributed to metabolic improvements, such as weight loss, insulin sensitivity, and blood glucose and insulin levels [14-16]. Except for the peripheral organs, FGF21 has been detected in different brain regions, including the cortex, hippocampus, striatum, and hypothalamus, and is involved in different neurophysiological functions [13]. Geller et al. demonstrated that hypothalamic tanycytes regulate lipid homeostasis via the secretion of FGF21 [17]. Timper et al. reported that increased FGF21 expression in astrocytes contributed to an improvement in systemic glucose homeostasis and memory formation via glucagon-like peptide signaling [18]. Katsu-Jiménez et al. observed that FGF21 enhanced the utilization 
of ketone bodies via AMP-activated protein kinase activation in neurons [19]. Douris et al. identified that FGF21 activated the sympathetic nervous system and induced peripheral thermogenesis [20]. Moreover, Chen et al. reported that the PP2A/MAPK/HIF-1a pathway was involved in the FGF21-mediated beneficial effects in pathologies like Alzheimer's disease (AD) [21]. However, the specific target of FGF21 in the central nervous system (CNS) remains unclear.

Metabonomics is a systemic biological approach used to screen for characteristic metabolites and their perturbed pathways in complex diseases by utilizing information related to pathological factors or by monitoring the effects of drugs and their mechanisms of action [22-26]. Nuclear magnetic resonance (NMR) analysis has high reproducibility and quantitative advantages, because it requires little sample pretreatment [27]. We have previously examined disturbances in the glutamate-glutamine cycle in the hippocampal regions of $d b / d b$ mice by using NMR-based metabonomics [28]. Further, we integrated molecular biology approaches to identify the glycolytic pathway and lactate levels, which were closely related to the pathogenesis of DACD [29-32]. By applying the same strategies, we also analyzed the basic FGF-remodeled metabolic phenotypes in the $d b / d b$ mice, which involved reductions in oxidative stress and apoptosis mediated by reactive oxygen species signaling [33].

These previous studies clearly demonstrated that a combination of metabonomics and molecular biology approaches can identify precursor-product relationships that drive perturbations, thereby providing us a better understanding of therapeutic targets as well as highly reliable results. In the present study, we established a streptozotocin (STZ)-induced type 1 DACD mouse model. Thereafter, we integrated the aforementioned technologies to explore whether exogenous FGF21 administration could have a protective effect on learning and memory after a hyperglycemic insult and to determine its relationship with PI3K-dependent lactate uptake and lactate dehydrogenase-B (LDH-B)-dependent lactate usage.

\section{Methods}

\section{Subjects}

Six-week-old male C57BL/6 mice (weight, 18-22 g) were purchased from Shanghai Slack Laboratory Animal Co., Ltd., and raised in specific-pathogen-free conditions at the Laboratory of the Experimental Animal Center of Wenzhou Medical University, with regulated humidity and temperature and a 12/12 h light-dark cycle. During the entire experiment, mice were fed with standard rat chow and tap water. All the experiments followed the National Institutes of Health Guide for the Care and Use of Laboratory Animals. The Institutional Animal Care and Use Committee of Wenzhou Medical University also approved the experiments (document number: wydw2012-0083). We also took steps to minimize the suffering and numbers of mice used.

In the experiment, mice were randomly divided into three groups: control, diabetic, and FGF21-treated diabetic (FGF21) groups. First, T1D was induced using streptozotocin (STZ, i.p., $50 \mathrm{mg} / \mathrm{kg}$ ), which was freshly prepared in $0.1 \mathrm{M}$ citrate buffer $(\mathrm{pH} 4.2-4.5)$, for five consecutive days. The control mice were 
administered an identical volume of the vehicle. Random blood glucose level in a blood sample drawn from the tail was measured $72 \mathrm{~h}$ later using a strip-operated blood glucose monitoring system (One Touch Ultra, Lifescan). Mice with blood glucose levels higher than $11.10 \mathrm{mM}$ were defined as diabetic mice [34]. After inducing hyperglycemia for 9 weeks, the diabetic mice were subdivided into two groups that received either the vehicle or FGF21 (2 mg/kg, i.p.) daily for four consecutive weeks. The control and untreated diabetic groups received sterile saline. The recombinant human FGF21 used in the study was expressed and purified according to previously described procedures [35].

\section{Morris water maze test}

The Morris water maze (MWM) test was performed as previously described [36, 37]. Briefly, after the drug or vehicle administration, the mice in each group were selected to perform a learning task in the MWM. The maze consisted of a white pool (diameter, $200 \mathrm{~cm}$; depth, $50 \mathrm{~cm}$ ) filled with a mixture of water and a non-toxic white dye (temperature, $26 \pm 2^{\circ} \mathrm{C}$ ). The behavior of the mice was traced using a camera connected to a XR-XM101 analysis system (Xinruan Information Technology Co. Ltd, Shanghai). The pool had four quadrants, and each orientation was designated as a starting position (North, South, East, or West). The pool also had a camouflaged escape platform submerged $2 \mathrm{~cm}$ below the water surface. The platform was placed in the middle of the second quadrant. The mice were trained for 4 days, and on each training day, the mice were placed in the four quadrants for 20 min intervals. The trial was started by placing a mouse at one of the starting points, with its back facing the platform. The trial was terminated when the mouse reached and stood on the platform, but the mouse was left on the platform for an additional $10 \mathrm{~s}$. However, if a mouse could not find the platform within $60 \mathrm{~s}$, it was guided and placed on the platform for $20 \mathrm{~s}$. During the spatial navigation test, all the mice were trained four times each day. On the 5th day, the probe trial was carried out, wherein the mice were allowed to swim for $60 \mathrm{~s}$, with the platform removed. The swimming distance, latency to find the platform, the number of crossings over the platform, and the time in the target quadrant were measured. After training, each mouse was removed from the pool, dried, and returned to its cage.

\section{Hippocampal samples preparation}

Twenty-four hours after the end of the MWM test, the mice were euthanized and their hippocampal tissues were dissected immediately, snap-frozen in liquid nitrogen, and stored at $-80^{\circ} \mathrm{C}$. The preparation of the brain samples and acquisition of ${ }^{1} \mathrm{H}-\mathrm{NMR}$ spectra were performed as previously described [38, 39]. Briefly, the frozen hippocampal tissues were weighed carefully and placed in centrifuge tubes. Methanol $(4 \mathrm{~mL} / \mathrm{g})$ and water were added into the tube immediately, homogenized at $4^{\circ} \mathrm{C}$, and mixed by vortexing. Chloroform $(2 \mathrm{~mL} / \mathrm{g})$ and distilled water were then added into the tube and mixed again. The tube was kept on ice for $15 \mathrm{~min}$, and then centrifuged for $15 \mathrm{~min}$ at $4^{\circ} \mathrm{C}$. The obtained aqueous extracts were then dissolved in $600 \mu \mathrm{L}$ of $99.5 \% \mathrm{D}_{2} \mathrm{O}$ for ${ }^{1} \mathrm{H}-\mathrm{NMR}$ spectroscopy.

\section{Multivariate pattern recognition analysis of ${ }^{1} \mathrm{H}-\mathrm{NMR}$ spectra}

The detailed acquisition protocol of ${ }^{1} \mathrm{H}-\mathrm{NMR}$ spectra has been previously described $[40,41]$. All NMR spectra were phased and corrected, and then data-reduced to 1,100 integrated regions corresponding to 
the region of $\delta 10-0$ by using the Topspin 2.1 software. The $\delta 4.6-5.0$ region was removed to eliminate artifacts related to residual water resonance. The spectral segments were normalized to the total of the spectral intensity. The normalized integral values were subjected to multivariate pattern recognition analysis using the SIMCA-P ${ }^{+}$V12.0 software package (Umetrics, Umea, Sweden). Supervised partial least squares-discriminant analysis (PLS-DA) was performed for class discrimination and biomarker identification [42]. Metabolites were assigned using Chenomx Profiler, a module of Chenomx NMR Suite version 7.7 evolution edition (Chenomx, Inc., Edmonton, AB, Canada) and the Human Metabolome Database (version 3.6).

Data were visualized using a principal component score plot to provide the most efficient representation of the data, wherein each point represented an individual spectrum. The score plots were used to visualize the separation between the groups. The loading plots, which were colored according to the absolute value of the correlation coefficient, could identify how the metabolites contributed to the separation of the groups. The scores and loading plots complemented each other. A leave-one-out crossvalidation and permutation test (200 times) on the first component was also applied to estimate the robustness and credibility of the PLS-DA model. If the plots showed that the $\mathrm{Q}^{2}$ regression line had a negative intercept and that the $\mathrm{R}^{2}$ values on the left were thus lower than those of the original point, the PLS-DA model was considered robust and credible. Meanwhile, three additional parameters were calculated: $\mathrm{R}^{2} \mathrm{X}$ and $\mathrm{R}^{2} \mathrm{Y}$, which explained the variance in the matrix of spectrum data and class membership, respectively, and $\mathrm{Q}^{2}$, which indicated the predictive capability of the model. These parameters are commonly used to determine the quality of a model, with values of $\mathrm{R}^{2}$ and $\mathrm{Q}^{2}$ close to 1.0 representing an excellent model [43].

\section{LDH activity assessment}

LDH activity was determined using a protocol detailed in our previous study.[32] Briefly, to determine the LDH lactate to pyruvate $(\mathrm{L} \rightarrow \mathrm{P})$ activity, we used an LDH kit (Jiancheng Bioengineering Institute, Nanjing) according to the manufacturer's instructions. $\mathrm{LDH} \mathrm{L} \rightarrow \mathrm{P}$ activity was detected at $25^{\circ} \mathrm{C}$ by measuring sample absorbance at $430 \mathrm{~nm}$ wavelength. For determining $\mathrm{LDH} \mathrm{P} \rightarrow \mathrm{L}$ activity, we used an assay designed on the basis of a procedure documented in the literature [44]. Protein lysates were diluted at a concentration of $0.05 \mathrm{mg} / \mathrm{mL}$ in $500 \mathrm{mM}$ potassium phosphate buffer (PPB) and were added to the LDH assay reagent containing $100 \mathrm{mM}$ pyruvate and $\beta$-nicotinamide adenine dinucleotide (NADH) in $500 \mathrm{mM}$ PPB (5 mg/20 mL; pH 7.5). Changes in NADH absorbance were measured at $25^{\circ} \mathrm{C}$, at 1-min intervals for $10 \mathrm{~min}$, at $340 \mathrm{~nm}$ wavelength. LDH total activity was calculated in IU/mg protein and expressed as the $P: L$ ratio $(L D H P \rightarrow L / L D H L \rightarrow P)$.

\section{ATP levels measurement}

The mouse hippocampal tissue/cell samples were homogenized and lysed, and the ATP content was detected using the Enhanced ATP Assay Kit (Beyotime Institute of Biotechnology, Shanghai) according to the manufacturer's instructions. 


\section{NAD ${ }^{+}$and NADH contents determination}

The mouse hippocampal tissues samples (10-20 mg) were homogenized, and the NAD ${ }^{+} / \mathrm{NADH}$ Assay Kit with WST-8 (Beyotime Institute of Biotechnology, Shanghai) was used to detect the NAD ${ }^{+}$and NADH contents.

\section{Reverse transcription-polymerase chain reaction analysis}

The mouse brain tissue samples (10-20 mg) were homogenized in TRIzol reagent (Invitrogen, Carlsbad, $\mathrm{CA}$ ) to extract total RNA. The reverse transcription (RT) of RNA into cDNA was performed by using the PrimeScript ${ }^{\mathrm{TM}}$ Real-Time Reagent Kit (Takara, RR037A). The polymerase chain reaction (PCR) analysis was performed using CFX96 Touch $^{\text {TM }}$ Real-Time PCR Detection System (Bio-Rad, Hercules, CA). The primer sequences are provided in supplemental Table S1.

\section{Cells culture and condition medium testing}

C6 astrocyte cells were cultured in Dulbecco's Modified Eagle Medium (DMEM, Invitrogen, Carlsbad, CA) containing $10 \%$ fetal bovine serum (FBS, Gibco) and 1\% antibiotics. SH-SY5Y neuron cells were cultured in F12 Medium supplemented with 10\% FBS and $1 \%$ antibiotics. They were incubated in $37^{\circ} \mathrm{C}$ and $5 \%$ of $\mathrm{CO}_{2}$ volume fraction.

C6 cells were cultured with normal glucose, high glucose (HG) for $48 \mathrm{~h}$. Then astrocyte-conditioned medium (ACM) were collected. After filtration, SH-SY5Y cells were respectively treated with ACM and FGF21 for further $48 \mathrm{~h}$. Refer to Figure $6 \mathrm{C}$ for the CM testing process $[45,46]$.

\section{Western blot analysis}

We used buffer containing 1\% protease and phosphatase inhibitors (Beyotime Biotechnology Institute) to extract the total protein from brain tissues and cell. Protein samples were loaded and electrophoresed, and then transferred to polyvinylidene fluoride membranes. After electrophoresis, the membranes were incubated in 1×TBST containing 5\% skimmed milk for $2 \mathrm{~h}$. Thereafter, the membranes were placed in the primary antibody and incubated overnight at $4{ }^{\circ} \mathrm{C}$. The primary antibodies used were as follows: MCT1 (1:1000; 20139-1-AP, Proteintech), MCT2 (1:1000; SC-166925, Santa Cruz Biotechnology), MCT4 (1:1000; 22787-1-AP, Proteintech), LDHA (1:1000; 3582S, Cell Signaling Technology), LDH-B (1:1000; 14824-1-AP, Proteintech), c-Fos (1:1000; 2250S, Cell Signaling Technology), EGR1 (1:1000; 97249S, Cell Signaling Technology), SYP (1:1000; ab184176, Abcam), PSD95 (1:1000; 3409S, Cell Signaling Technology), PPI3K(1:1000; 17366S, Cell Signaling Technology), PI3K(1:1000; 4249S, Cell Signaling Technology), P-Akt (1:1000; 4060S, Cell Signaling Technology), Akt (1:1000; 4691S, Cell Signaling Technology), p-mTOR (1:1000; 5536S, Cell Signaling Technology), mTOR (1:1000; 2983S, Cell Signaling Technology), P-P70 (1:1000; 9250S, Cell Signaling Technology), P70 (1:1000; 2708S, Cell Signaling Technology), GAPDH (1:1000; 60004-1-Ig, Beyotime Institute of Biotechnology) and $\beta$-Actin (1:1000; A418, Beyotime Institute of Biotechnology). After washing with $1 \times$ TBST three times, the membranes were incubated with the 
secondary antibodies (goat anti-mouse IgG $(\mathrm{H}+\mathrm{L}), 1: 5000$, SA00001-1, Proteintech; goat anti-rabbit IgG $(\mathrm{H}+\mathrm{L}), 1: 5000$, SA00001-2, Proteintech) for $1 \mathrm{~h}$ at room temperature. We used the ChemiDoc XRS ${ }^{+}$ Imaging System (Bio-Rad) to detect the bands and Image-Pro Plus 6.0 software to analyze the gray values of the bands.

\section{Histological analysis}

The brain tissues were isolated and fixed in $4 \%$ paraformaldehyde for at least $24 \mathrm{~h}$. Thereafter, they were embedded in paraffin and sectioned using a slicing microtome (Leica, Germany).

For the MCT2 immunohistochemical staining experiments, paraffin sections were placed in an incubator at $60^{\circ} \mathrm{C}$ for $1 \mathrm{~h}$. The dewaxed and dehydrated paraffin sections were then incubated in $3 \% \mathrm{H}_{2} \mathrm{O}_{2}$ for 10 min and incubated in boiling citrate buffer for 5-10 min. Thereafter, the sections were blocked with $5 \%$ bovine serum albumin for $1 \mathrm{~h}$. The paraffin sections were then incubated with the MCT2 antibody (1:50; SC-166925, Santa Cruz Biotechnology) overnight at $4^{\circ} \mathrm{C}$. After washing the sections three times in $1 \times$ phosphate-buffered saline (PBS), they were incubated with the secondary antibody (goat anti-mouse IgG, 1:200; SA00001-1, Proteintech) at $37^{\circ} \mathrm{C}$ for $1 \mathrm{~h}$ and stained using a DAB kit (ZLI-9017, ZSGB-BIO). Images of the stained sections were captured using a Nikon ECLIPSE Ti microscope.

For the LDH-B immunofluorescence experiments, most of the protocols were similar to those used in the aforementioned immunohistochemical analysis. The only difference was that the sections were incubated with the fluorescent secondary antibody after washing three times in PBS.

\section{Cell immunofluorescence}

The cells were spread in a 24-hole plate containing the cover glass at a density of $2 \times 10^{4} /$ hole, after washing the sections three times in PBS, they were incubated with the $4 \%$ Polyformaldehyde for 45 min. Then $0.5 \%$ Trition-X-100 punched for $15 \mathrm{~min}$, the plates were blocked with $5 \%$ bovine serum albumin. The plates were then incubated with the MCT2 antibody (1:200; SC-166925, Santa Cruz Biotechnology) overnight at $4^{\circ} \mathrm{C}$. After washing the plates three times in PBS, they were incubated with the fluorescent secondary antibody for $1 \mathrm{~h}$.

\section{Statistics}

Data are presented as mean \pm SEM. All data were analyzed using one-way analyses of variance (ANOVA) followed by Scheffe's post-hoc test. Values of $p<0.05$ were considered statistically significant. SPSS for Windows, Version 13.0 (SPSS Inc., Chicago, IL) was used for all statistical tests. The figures were generated using Prism 5.0 software (GraphPad Software, Inc., San Diego, CA).

\section{Results}

\section{Effects of FGF21 on blood glucose, body weight, learning and memory performance in diabetic mice}


In the present study, we established an STZ-induced T1D mouse model and treated these mice with 28 consecutive days of FGF21 (2 mg/Kg) after STZ administration for four weeks. We found FGF21 could reduce high blood glucose in T1D mice but fail to restored weight loss caused by diabetes (Fig. 1A-B). Oral glucose tolerance tests or insulin tolerance tests also showed improving glucose tolerance in the mice treated with FGF21 (Fig. 1C-F). To investigate whether FGF21 administration can alleviate long-term learning and memory defects in diabetic mice, we used the MWM test and RT-PCR analysis to examine the related indicators. Figure 2 shows the swimming behavior indicators and immediate early gene (IEG) levels in the differently treated mice. As expected, the diabetic mice showed a longer escape latency, as well as a shorter platform crossing time and target quadrant time, than did the controls, suggesting impairments in their long-term spatial memory formation due to the hyperglycemic insult. However, the FGF21-treated mice displayed significant improvements in escape latency compared to the untreated diabetic mice (Fig. 2A). We removed the platform after the last training session, the mice in the three groups showed no differences in swimming distance (Fig. 2B-C), suggesting similarity in their activity in the probe trial. Nevertheless, FGF21 treatment could significantly improve the 24-h memory performance of diabetic mice, as shown by their platform crossing times and target quadrant time (Fig. 2D-E).

In addition, the molecular indicators underlying the process of long-term (24-hour) memory include the expressions of IEG products, such as early growth response 1 (Egr-1), proto-oncogene (c-Fos), activityregulated cytoskeletal-associated protein (Arc or Arg3.1), as well as several presynaptic (SYP) and postsynaptic proteins (PSD-93 and PSD-95). We found reduced expression levels of these proteins in the hippocampal extracts of diabetic mice. Nevertheless, FGF21 administration could restore both their mRNA (Fig. 2F) and protein levels (Fig. S1). Thus, both the MWM test and molecular indicators demonstrated that FGF21 administration could significantly alleviate the hippocampal-dependent spatial learning and long-term memory defects in diabetic mice.

\section{Metabolic phenotypes in the hippocampus of the mice}

A typical ${ }^{1} \mathrm{H}-\mathrm{NMR}$ spectrum obtained from the hippocampal extract of one mouse is shown in Figure $3 \mathrm{~A}-$ C. In total, 25 metabolites were identified, including energy metabolites (lactate, creatine, ADP, and AMP), tricarboxylic acid cycle (TCA) intermediates (succinate and fumarate), neurotransmitters (glutamate, $\mathrm{Y}^{-}$ aminobutyric acid [GABA], and glycine), antioxidants (taurine and glutathione), amino acids (leucine, aspartate, isoleucine, valine, alanine, $\mathrm{N}$-acetylaspartate [NAA], tyrosine, and phenylalanine), and others (phosphocholine, glycerophosphocholine, choline, myo-inositol, and acetate). These metabolites were used for the subsequent multivariate pattern recognition and quantitative analyses.

First, we performed a PLS-DA to examine the metabolic patterns in the three groups. The score plot showed a clear separation among the three groups (Fig. 3D), indicating their different metabolic profiles. We then performed permutation tests with 200 iterations to assess the possibility of model overfitting. The obtained parameters were $\mathrm{R}^{2} \mathrm{X}(\mathrm{cum})=0.525, \mathrm{R}^{2} \mathrm{Y}$ (cum) $=0.650$, and $\mathrm{Q}^{2}$ (cum) $=0.579$, and the $p$ value of cross-validated ANOVA was less than 0.001, which indicated that the PLS-DA model was highly reliable (Fig. 3E, Table S2). 


\section{Characteristic metabolite alterations in the DACD mice}

To identify the characteristic metabolites in the hippocampal extracts that were responsible for the differences among the groups, we applied a PLS-DA for pairwise comparison. The scores and corresponding loading plots with correlation coefficients $(|r|>1.0$ is labeled) are shown in Figure 4 . The PLS-DA score plots demonstrated significant differences between the diabetic and control groups $\left(R^{2} X\right.$ (cum) $=0.504, R^{2} Y($ cum $)=0.863, Q^{2}$ (cum) $=0.691, p<0.001$; Figure 3A), the FGF21 and control groups $\left(R^{2} X(\right.$ cum $)=0.570, R^{2} Y($ cum $)=0.870$, and $Q^{2}($ cum $)=0.771, p<0.001$; Figure 3B), and the diabetic and

FGF21 groups $\left(R^{2} X(\right.$ cum $)=0.458, R^{2} Y$ (cum) $=0.716$, and $Q^{2}$ (cum) $=0.437, p<0.01$; Fig. $4 C$ ). The quality parameters of each PLS-DA plot are shown in Table S2.

Simultaneously, we calculated the relative integrals of the metabolites in the three groups and compared their levels (Table S3). Compared to the control group, the diabetic group showed upregulated levels of lactate, creatine, taurine, and myo-inositol. In contrast, 15 metabolites were downregulated in the diabetic group, including acetate, NAA, GABA, glutamate, succinate, glutamine, glutathione, choline, phosphocholine, ADP, AMP, glycerophosphocholine, tyrosine, and phenylalanine. However, compared to diabetic mice, the FGF21-treated mice showed decreased levels of NAA, GABA, aspartate, creatine, taurine, and phenylalanine, but increased levels of lactate, acetate, succinate, choline, phosphocholine, glycerophosphocholine, and myo-inositol. Interestingly, the levels of some metabolites (i.e., lactate, myoinositol, NAA, GABA, and phenylalanine) in the FGF21 mice did not recover to the control levels, thereby suggesting that the pharmacological activity of FGF21 is complex and diverse.

Furthermore, to confirm characteristic alterations in the metabolic profiles after drug treatment, some metabolites with $|r|>1.0$ in the loading plots and $p<0.05$ in metabolic levels were ranked according to their variable importance in projection (VIP) scores (Fig. S2-3), in which VIP > 1 was set as the threshold value. Lactate had the highest VIP value in the plot, suggesting that the glycolytic pathway closely correlated with the effect of FGF21 treatment in DACD mice.

\section{FGF21 promotes lactate usage via LDH-B-dependent glycolysis activity}

In glycolysis, $\mathrm{LDH}-\mathrm{A}$ favors the reduction of pyruvate to lactate in the presence of $N A D H(P \rightarrow L)$. LDH-B is responsible for the opposite reaction, i.e., the oxidation of lactate to pyruvate in the presence of NAD ${ }^{+}$ $(L \rightarrow P)$, followed by the TCA cycle and ATP production in neurons (Fig. 5A) [47]. In the enzymatic activity assay, we observed a greater increase in $P \rightarrow L$ conversion and a greater decrease in $L \rightarrow P$ conversion in the diabetic mice than in the controls, which resulted in a total increase in $\mathrm{P} \rightarrow \mathrm{L}$ conversion and lactate accumulation. However, FGF21 treatment could restore these alterations, as reflected by the enhancement in the $L \rightarrow P$ pathway and lactate usage (Fig. $5 B-C$ ).

LDH has five isoenzymes, namely LDH $1-5$, and each isoform is composed of $M$ and $\mathrm{H}$ subunits, which are the gene products of LDH-A and LDH-B, respectively [32]. As expected, the hippocampal PCR data 
showed that LDH-A mRNA levels were upregulated by about 100\%, while LDH-B mRNA levels were downregulated by over $50 \%$ in the diabetic mice at 15 weeks. However, FGF21 treatment could restore all the alterations in the mRNA levels (Fig. 5D). Moreover, the changes in the levels of ATP and NAD ${ }^{+} / N A D H$, which are glycolytic $L \rightarrow P$ direction products, confirmed the altered LDH activity (Fig. 5E-F). Furthermore, the results of immunofluorescence staining of the hippocampal regions confirmed that the decreased expression of LDH-B in diabetic mice was reversed by FGF21 treatment (CA3 region; Fig. 5G). Western blot analysis also showed the same LDH-A and LDH-B expression trends (Fig. $5 \mathrm{H}$ ), which suggested that the changes in LDH protein are consistent with those in its activity and mRNA levels. Taken together, our data indicated that the higher lactate levels in the diabetic hippocampi were the result of elevated lactate production and reduced lactate usage. Nevertheless, FGF21 treatment could increase lactate usage in neurons by promoting lactate to pyruvate conversion, followed by ATP and NADH production.

\section{FGF21 promotes lactate uptake via the PI3K-dependent MCT2 pathway}

Lactate is transported through the cell membrane by different proton-linked monocarboxylate transporters (MCTs) [48]. In the CNS, MCT4 is expressed exclusively on astrocytes, while MCT1 is mainly detected in endothelial cells of blood vessels and glial cells, which can supply lactate to the surrounding neurons $[48,49]$. MCT2 is found in the axons, dendrites, and cell bodies of neurons [50]. We performed western blot and histological analyses to compare the protein levels of MCT1, MCT2, and MCT4 in the hippocampi of the mice. The results showed significant suppression of MCT2 protein levels in the diabetic mice, and these levels were restored after FGF21 treatment, indicating the restoration of lactate uptake into the neurons after drug administration (Fig. 6A-B). To determine if the enhancement in MCT2 protein synthesis occurs due to translational or transcriptional regulation, we also examined their mRNA levels via RT-PCR. However, as shown in Supplementary Fig. 4, FGF21 exerts no effects on MCT2 mRNA levels.

The activation of PI3K is involved in the effects of brain-derived neurotrophic factor (BDNF) and insulin growth factor-1 (IGF-1) on MCT2 expression [51, 52]. To determine the mechanism through which FGF21 enhanced MCT2 expression, we examined the signaling pathways by monitoring their phosphorylation levels in the hippocampal extracts. Thereafter, we determined the phosphorylation levels of Akt at Ser473, mTOR at Ser2448, S6 ribosomal protein at Ser235/236, using western blot analysis. Our results revealed greater suppression of phosphorylation protein expressions in the hippocampus of diabetic mice than in the controls, but this suppressed expression was restored after FGF21 administration (Fig. 6A).

In addition, we established an in vitro model in which cell condition culture with high glucose (HG) was applied, that was devoid of exogenous insulin, mimicking diabetic environment (Fig. 6C). The expression of MCT2 protein in SH-SY5Y cells was remarkably reduced under $75 \mathrm{mM}$ glucose astrocyte-conditioned culture (ACM, Fig. 7A-B). In addition, $75 \mathrm{mM} \mathrm{HG-ACM}$ treatment can significantly reduce the synaptic proteins, i.e. PSD-95, SYP, and EGR-1. c-Fos, while FGF21 (100 ng/ml) can restore these expressions (Fig. 7C-D), which were consistent with the in vivo results. Furthermore, FGF21 treatment also reversed 
LDH-B expressions and ATP levels in SH-SY5Y cell (Fig. 7E-G). Using an MCT2 inhibitor a-Cyano-4hydroxycinnamic acid (a-CHC, $2.5 \mathrm{mM}$ ), we also found that restoration of LDH-B and ATP by FGF21 in HG situation were potently abrogated (Fig. 7E-G).

To validate the role of $\mathrm{PI} 3 \mathrm{~K} / \mathrm{AKT} / \mathrm{mTOR}$ in FGF21-mediated alleviation of bioenergy dysfunction induced by HG, we used PI3K inhibitor LY294002 $(10 \mu \mathrm{M})$ and mTOR inhibitor Rapamycin $(20 \mathrm{ng} / \mathrm{mL})$ in vitro. Consistently, we found that activations of PI3K, m-TOR and MCT2 expressions by FGF21 in SH-SY5Y cells were markedly compromised (Fig. 6D-G). The results of immunofluorescence were consistent with the western blotting data (Fig. $6 \mathrm{H}-\mathrm{I})$. This in vitro model further strengthened the notion that MCT2 plays an important role in FGF21-mediated improvement in cognition function. Taken together, these results suggested that the enhancement of PI3K-dependent MCT2 protein might be the vital molecular mechanism underlying the effects of FGF21 in DACD mice (Fig. 8).

\section{Discussion}

FGF21, which is a hormone that belongs to the FGF family, exerts several beneficial effects on diabetes and associated complications [53]. Furthermore, exogenously administered FGF21 can cross the blood brain barrier via simple diffusion, making it a potential therapeutic medicine for CNS diseases [54]. In the present study, we found that FGF21 could rescue blood glucose levels, and improve learning and memory impairments in mice with STZ-induced T1D. These results are consistent with the previous studies [53]. Taken together, the present findings demonstrated that FGF21 administration to DACD mice 1) restored long-term learning and memory defects; 2) improved hippocampal bioenergetic metabolite levels; 3 ) promoted LDH-B-dependent lactate usage in neurons; 4) increased PI3K-dependent MCT2 levels (Fig. 8).

\section{Bioenergetic pathway alterations in DACD mice}

Following STZ injection for 9 weeks, we observed reduced MWM test performance and decreased synaptic plasticity and IEG molecule levels in the hippocampal regions of diabetic mice than in those of the controls. Both results indicated the presence of hippocampal-dependent learning and long-term (24 hours after last training) memory defects in the diabetic mice, i.e., the occurrence of DACD. Therefore, the metabolic changes in the hippocampus might be directly related to the pathogenesis of DACD. The NMRbased metabonomic analysis of hippocampal extracts also revealed that the levels of energy metabolites (ADP, AMP, and creatine phosphate) showed a downward trend, suggesting a decline in energy production in the diabetic mice. As phosphate compounds, both adenosine phosphate and creatine phosphate are high-energy reservoirs, which are crucial for sustaining brain functions, i.e., the maintenance of ion gradients and uptake of neurotransmitters [55]. The human brain is known to consume $20 \%$ of the energy in a resting state, while only accounting for $2 \%$ of the body weight [56]. Therefore, the decline in energy production in the hippocampal regions may lead to the pathogenesis of DACD.

Glucose metabolism is a catabolic process that produces energy. Glucose is first converted into pyruvate, which is then transformed into lactate by anaerobic glycolysis, or is metabolized in the TCA cycle to 
produce additional reducing equivalents that drive the electron transport chain and ATP production. Importantly, the disruption of the glucose pathways can result in damages to neuronal function $[57,58]$. $A D$ is a common pathology of cognitive dysfunction among the elderly and is characterized by the accumulation of cerebral amyloid- $\beta$ peptide and tau protein phosphorylation [59]. Multiple studies have suggested that energy metabolism impairment precedes neurodegeneration and cognitive decline in patients with $A D[60]$.

Similarly, the decreased succinate levels in hippocampal regions indicated inhibited aerobic glucose metabolism in the diabetic mice. This accumulated lactate may result from reduced lactate usage in neurons or increased lactate production in the diabetic state, which were consistent with the findings of our previous studies $[28,31,61]$. Using $\left[2-{ }^{13} \mathrm{C}\right]$ acetate and $\left[1{ }^{-13} \mathrm{C}\right]$ glucose as tracer substrates, we previously identified inhibited pyruvate recycling in the neurons of diabetic animals $[7,30]$. Through in vitro primary cell culture, we further confirmed the decreased usage of lactate in neurons but not in astrocytes $[62,63]$. All these data suggested that the reduced usage of lactate in neurons was a crucial factor contributing to neuronal dysfunction and bioenergetic deficits in the diabetic mice.

The astrocyte-neuron lactate shuttle (ANLS) hypothesis proposes that in astrocytes, glucose is predominantly metabolized to lactate, which is also a primary fuel source for neuronal and synaptic activities [64-67]. Lactate is an effective neuroprotective metabolite, and exogenous lactate administration can rescue neuronal activity during glucose deprivation [46]. Currently, lactate is recognized as a source of energy as well as a signaling molecule or receptor agonist, modulating neuronal excitability, plasticity, and cognition $[68,69]$. Suzuki et al. identified the involvement of glycogen breakdown and lactate release from astrocytes in the long-term memory process [70]. In addition, the effects of lactate are mediated by NADH/NAD ${ }^{+}$-dependent NMDA receptor activity, which involves synaptic plasticity-related genes such as Egr-1, Arc, and c-Fos [71, 72]. Therefore, the effects of lactate on learning and memory are associated with direct or indirect redox or energy-dependent mechanisms, which may be attributed to NADH and ATP production in the glycolytic pathway that is also an underlying target of the drug.

\section{FGF21 alleviates DACD through promoting neuronal lactate usage}

FGF21 functions as an energy metabolism regulator and performs a pleiotropic function in glucose and energy metabolism [14-16]. Growing evidence has revealed the potential role of FGF21 in CNS diseases, in which it promotes mitochondrial antioxidant enzyme action and biogenesis, thereby enhancing neuronastrocyte interactions [73]. We also identified that FGF21 treatment could improve learning and memory impairments in diabetic mice using the MWM test and synaptic plasticity data, which were consistent with those of previous studies [74-76]. Furthermore, we determined that FGF21 modulated hippocampal lactate and succinate levels, indicating that its therapeutic effects involved glycolysis remodeling. 
Alterations in the glycolysis rate result in changes in the levels of pyruvate, lactate, and NADH. The greater the LDH-A/LDH-B activity ratio was enzymatically controlled, the more lactate was converted to pyruvate. Our data revealed that FGF21 alleviated learning and memory defects, with corresponding changes in the LDH-A/LDH-B activity ratios. LDH has different homo- or hetero-tetrameric isoforms transcribed by $L D H-A$ and $L D H-B$, and the ANLS hypothesis suggests they are predominantly present in astrocytes and neurons, respectively [77]. In this study, FGF21 directly contributed to the $L \rightarrow P$ conversion in neurons, accompanied by elevated ATP and NADH production.

Our results are similar to those recently reported by Sun et al.[46] They observed that FGF21 can rescue the ANLS system by increasing the expressions of LDH-A, LDH-B, MCT1, and MCT2, which are all reduced in an AD mouse model. Additionally, in an aging mouse model, scientists found decreased LDH-B expression in the hippocampus, which may be a major factor leading to a decline in cognition [78]. In the study, FGF21 ameliorated DACD by promoting the $L \rightarrow P$ conversion in neurons, i.e., the usage of lactate under the activity of LDH-B. Interestingly, we also found that FGF21 could stimulate the activity of LDH-A and increase the lactate content in the hippocampus. This finding was consistent with that of a previous oncological study, which found that FGF21 could directly phosphorylate LDH-A on the tyrosine residue $[79,80]$.

\section{FGF21 promotes neuronal lactate uptake via PI3K/Akt/mTOR-dependent MCT2 expressions}

MCT2 is predominantly expressed by the neuronal postsynaptic membrane. It allows the uptake of lactate, pyruvate, and ketone bodies across the plasma membrane as energy substrates [50]. Decreased hippocampal expressions of MCT2 have been reported in previous studies on $A D$ and diabetic animal models [81, 82]. The MCT2-related depletion of the lactate pool limits the activities of LDH-B, causes glycolytic shifts ( $L \rightarrow P$ conversion), affects NADH and ATP production, thereby leading to learning and memory defects. Recently, Netzahualcoyotzi and Pellerin confirmed that neuronal MCT2 is involved in 24hour and 7-day long-term memory formation, but not in 90-minute short-term memory formation [83]. BDNF, insulin, and IGF-1, which are implicated in the long-term memory process and modulate synaptic plasticity, can promote the protein expression of MCT2 [51, 52]. Similarly, our study also showed that FGF21 increased MCT2 expression, but not the expressions of the glial transporters MCT1 and MCT4. Thus, one of the mechanisms through which FGF21 alleviates long-term memory defects might be the promotion of MCT2-dependent lactate uptake, in parallel with ATP and NADH production.

As an endocrine regulator, FGF21 has many beneficial effects on cell metabolism by stimulating glucose and lipoprotein uptake in liver cells $[84,85]$. When FGF21 binds with its receptor, it contributes to the phosphorylation of downstream signaling molecules, such as MAPK, PI3K, signal transducer and activator of transcription, and phosphoinositide phospholipase $C_{-\gamma}-[13,86]$. In our study, we identified the role of the concomitant activation of the PI3K pathway in regulating the protein expression of MCT2 in the hippocampal regions, and both these molecules have been classically implicated in translation regulation similar to BDNF, insulin, and IGF-1 [51, 52]. 
As a downstream protein in the PI3K pathways, MCT2 can interact with glutamatergic AMPA receptor (GluR) subtype GluR2, which is involved in glutamatergic transmission and long-term potentiation [87]. Our observation that FGF21 could upregulate MCT2 in protein levels was consistent with the finding of a previous study that energy metabolism was coupled to synaptic plasticity after BDNF treatment [88]. We hypothesize that to meet high energy demands, the translational regulation of MCT2 are increased to facilitate energy supply and neuronal function under the condition of enhanced synaptic transmission or pathological insult, i.e., in diabetes.

\section{Conclusion}

The present study demonstrated that FGF21 treatment in mice with STZ-induced DACD could restore long-term learning and memory defects by promoting LDH-B-dependent conversion of lactate to pyruvate, followed by ATP and NADH production. The study further suggested that the regulation of PI3Kdependent MCT2 expression was a potential target mediating the beneficial effects of FGF21 on DACD. Considering the critical roles of MCT2 and LDH-B on lactate uptake and usage, respectively, our results support the possibility of a link between neuronal bioenergetics and synaptic plasticity. Furthermore, our findings suggest that the combination of metabonomics and molecular biology is helpful for studying potential molecular mechanisms and drug targets involved in various pathologies. Several limitations should be considered: First, although our data showed that FGF21 treatment for 4 weeks effectively improved learning and long-term memory defects in the mice with DACD, we do not know whether a 4week-treatment period is optimal for producing the best therapeutic effects. Second, among the four types of FGF receptors, FGF21 can interact with at least FGFR 1-3 $[13,86]$. However, our understanding of which FGFR mediates FGF21 signal transduction is incomplete. Lastly, the protein $\beta$-klotho is required for FGF21 to exert its effects in vivo [89]. Therefore, further studies are warranted to determine the protein involved in the FGF21-mediated stimulation of hippocampal neurons.

\section{Declarations}

\section{Ethics approval}

All the experiments followed the National Institutes of Health Guide for the Care and Use of Laboratory Animals. The Institutional Animal Care and Use Committee of Wenzhou Medical University also approved the experiments (document number: wydw2012-0083). We also took steps to minimize the suffering and numbers of mice used.

\section{Consent to participate}

Not applicable

\section{Consent for publication}

Not applicable 
Availability of data and materials

The datasets generated during and/or analyzed during the current study are available from the corresponding author on reasonable request.

\section{Competing interests}

The authors declare that they have no competing interests.

\section{Funding}

This study was supported by the Natural Science Foundation of Zhejiang Province (No. LY22H070003), and the National Natural Science Foundation of China (Nos.: 81770830, 21974096, 81771386).

\section{Authors' contributions}

LZ. and HG. contributed to experimental design and writing of the manuscript. HJ. and LZ. contributed to animal experiment data acquisition. DS., QY., JX., JY., CL., HZ. contributed to data analysis and result interpretation. All authors have read and approved the final manuscript.

\section{Acknowledgements}

Not applicable

\section{Authors' information}

Affiliations

School of Pharmaceutical Sciences, Wenzhou Medical University, Wenzhou 325035, Zhejiang, China

\#Liangcai Zhao and Haowei Jiang contributed equally to this work.

Corresponding Author

*Hongchang Gao, Email: gaohc27@wmu.edu.cn『

*Liangcai Zhao, Email: zhaoliangcai@wmu.edu.cn

\section{References}

1. Shalimova A, Graff B, Gasecki D, Wolf J, Sabisz A, Szurowska E, Jodzio K, Narkiewicz K (2019) Cognitive Dysfunction in Type 1 Diabetes Mellitus. J Clin Endocrinol Metab 104 (6):2239-2249

2. Fischer AL, de Frias CM, Yeung SE, Dixon RA (2009) Short-term longitudinal trends in cognitive performance in older adults with type 2 diabetes. J Clin Exp Neuropsychol 31 (7):809-822 
3. Samaras K, Lutgers HL, Kochan NA, Crawford JD, Campbell LV, Wen W, Slavin MJ, Baune BT, Lipnicki DM, Brodaty H, Trollor JN, Sachdev PS (2014) The impact of glucose disorders on cognition and brain volumes in the elderly: the Sydney Memory and Ageing Study. Age (Dordr) 36 (2):977-993

4. Gregg EW, Yaffe K, Cauley JA, Rolka DB, Blackwell TL, Narayan KM, Cummings SR (2000) Is diabetes associated with cognitive impairment and cognitive decline among older women? Study of Osteoporotic Fractures Research Group. Arch Intern Med 160 (2):174-180

5. Yi SS, Hwang IK, Kim DW, Shin JH, Nam SM, Choi JH, Lee CH, Won MH, Seong JK, Yoon YS (2011) The Chronological Characteristics of SOD1 Activity and Inflammatory Response in the Hippocampi of STZ-Induced Type 1 Diabetic Rats. Neurochemical Research 36 (1):117-128

6. Ye L, Wang F, Yang RH (2011) Diabetes impairs learning performance and affects the mitochondrial function of hippocampal pyramidal neurons. Brain Research 1411:57-64

7. Bornstein NM, Brainin M, Guekht A, Skoog I, Korczyn AD (2014) Diabetes and the brain: issues and unmet needs. Neurol Sci 35 (7):995-1001

8. Wessels AM, Scheltens P, Barkhof F, Heine RJ (2008) Hyperglycaemia as a determinant of cognitive decline in patients with type 1 diabetes. European journal of pharmacology 585 (1):88-96

9. McCrimmon R, Ryan C, Frier B (2012) Diabetes and cognitive dysfunction. Lancet 379 (9833):22912299

10. Mäkimattila S, Malmberg-Cèder K, Häkkinen A-M, Vuori K, Salonen O, Summanen P, Yki-Järvinen H, Kaste M, Heikkinen S, Lundbom N (2004) Brain metabolic alterations in patients with type 1 diabetes-hyperglycemia-induced injury. Journal of Cerebral Blood Flow \& Metabolism 24 (12):13931399

11. Gabbay KH, Merola LO, Field RA (1966) Sorbitol pathway: presence in nerve and cord with substrate accumulation in diabetes. Science 151 (3707):209-210

12. Chung SS, Ho EC, Lam KS, Chung SK (2003) Contribution of polyol pathway to diabetes-induced oxidative stress. Journal of the American Society of Nephrology 14 (suppl 3):S233-S236

13. Sa-Nguanmoo P, Chattipakorn N, Chattipakorn SC (2016) Potential roles of fibroblast growth factor 21 in the brain. Metab Brain Dis 31 (2):239-248

14. Inagaki T, Dutchak P, Zhao G, Ding X, Gautron L, Parameswara V, Li Y, Goetz R, Mohammadi M, Esser V, Elmquist JK, Gerard RD, Burgess SC, Hammer RE, Mangelsdorf DJ, Kliewer SA (2007) Endocrine regulation of the fasting response by PPARalpha-mediated induction of fibroblast growth factor 21 . Cell Metab 5 (6):415-425

15. Potthoff MJ, Inagaki T, Satapati S, Ding X, He T, Goetz R, Mohammadi M, Finck BN, Mangelsdorf DJ, Kliewer SA, Burgess SC (2009) FGF21 induces PGC-1 alpha and regulates carbohydrate and fatty acid metabolism during the adaptive starvation response. Proc Natl Acad Sci U S A 106 (26):1085310858

16. Li X (2019) The FGF metabolic axis. Front Med 13 (5):511-530

17. Geller S, Arribat Y, Netzahualcoyotzi C, Lagarrigue S, Carneiro L, Zhang L, Amati F, Lopez-Mejia IC, Pellerin L (2019) Tanycytes Regulate Lipid Homeostasis by Sensing Free Fatty Acids and Signaling 
to Key Hypothalamic Neuronal Populations via FGF21 Secretion. Cell Metab 30 (4):833-844 e837

18. Timper K, Del Rio-Martin A, Cremer AL, Bremser S, Alber J, Giavalisco P, Varela L, Heilinger C, Nolte H, Trifunovic A, Horvath TL, Kloppenburg P, Backes H, Bruning JC (2020) GLP-1 Receptor Signaling in Astrocytes Regulates Fatty Acid Oxidation, Mitochondrial Integrity, and Function. Cell Metab 31 (6):1189-1205 e1113

19. Katsu-Jimenez Y, Gimenez-Cassina A (2019) Fibroblast growth Factor-21 promotes ketone body utilization in neurons through activation of AMP-dependent kinase. Mol Cell Neurosci 101:103415

20. Douris N, Stevanovic DM, Fisher FM, Cisu TI, Chee MJ, Nguyen NL, Zarebidaki E, Adams AC, Kharitonenkov A, Flier JS, Bartness TJ, Maratos-Flier E (2015) Central Fibroblast Growth Factor 21 Browns White Fat via Sympathetic Action in Male Mice. Endocrinology 156 (7):2470-2481

21. Chen S, Chen ST, Sun Y, Xu Z, Wang Y, Yao SY, Yao WB, Gao XD (2019) Fibroblast growth factor 21 ameliorates neurodegeneration in rat and cellular models of Alzheimer's disease. Redox Biol 22:101133

22. Nicholson JK, Lindon JC, Holmes E (1999) 'Metabonomics': understanding the metabolic responses of living systems to pathophysiological stimuli via multivariate statistical analysis of biological NMR spectroscopic data. Xenobiotica 29 (11):1181-1189

23. Lu J, Xie G, Jia W (2013) Metabolomics in human type 2 diabetes research. Front Med 7 (1):4-13

24. Chen WL, Wang JH, Zhao AH, Xu X, Wang YH, Chen TL, Li JM, Mi JQ, Zhu YM, Liu YF, Wang YY, Jin J, Huang H, Wu DP, Li Y, Yan XJ, Yan JS, Li JY, Wang S, Huang XJ, Wang BS, Chen Z, Chen SJ, Jia W (2014) A distinct glucose metabolism signature of acute myeloid leukemia with prognostic value. Blood 124 (10):1645-1654

25. Luo P, Yin P, Hua R, Tan Y, Li Z, Qiu G, Yin Z, Xie X, Wang X, Chen W, Zhou L, Wang X, Li Y, Chen H, Gao L, Lu X, Wu T, Wang H, Niu J, Xu G (2017) A large-scale, multi-center serum metabolite biomarkers identification study for the early detection of hepatocellular carcinoma. Hepatology

26. Hasin Y, Seldin M, Lusis A (2017) Multi-omics approaches to disease. Genome Biol 18 (1):83

27. Verpoorte R, Choi Y, Mustafa N, Kim H (2008) Metabolomics: back to basics. Phytochemistry Reviews 7 (3):525-537

28. Zheng Y, Yang Y, Dong B, Zheng H, Lin X, Du Y, Li X, Zhao L, Gao H (2016) Metabonomic profiles delineate potential role of glutamate-glutamine cycle in $\mathrm{db} / \mathrm{db}$ mice with diabetes-associated cognitive decline. Mol Brain 9:40

29. Zheng H, Zheng Y, Wang D, Cai A, Lin Q, Zhao L, Chen M, Deng M, Ye X, Gao H (2016) Analysis of neuron-astrocyte metabolic cooperation in the brain of $\mathrm{db} / \mathrm{db}$ mice with cognitive decline using $13 \mathrm{C}$ NMR spectroscopy. J Cereb Blood Flow Metab

30. Wang N, Zhao L-C, Zheng Y-Q, Dong M-J, Su Y, Chen W-J, Hu Z-L, Yang Y-J, Gao H-C (2015) Alteration of interaction between astrocytes and neurons in different stages of diabetes: a nuclear magnetic resonance study using [1-13C] glucose and [2-13C] acetate. Molecular neurobiology 51 (3):843-852

31. Dong M, Ren M, Li C, Zhang X, Yang C, Zhao L, Gao H (2018) Analysis of Metabolic Alterations Related to Pathogenic Process of Diabetic Encephalopathy Rats. Front Cell Neurosci 12:527 
32. Zhao L, Dong M, Ren M, Li C, Zheng H, Gao H (2018) Metabolomic Analysis Identifies Lactate as an Important Pathogenic Factor in Diabetes-associated Cognitive Decline Rats. Mol Cell Proteomics 17 (12):2335-2346

33. Wei T, Shu Q, Ning J, Wang S, Li C, Zhao L, Zheng H, Gao H (2020) The Protective Effect of Basic Fibroblast Growth Factor on Diabetic Nephropathy Through Remodeling Metabolic Phenotype and Suppressing Oxidative Stress in Mice. Front Pharmacol 11:66

34. Zhang T, Zheng H, Fan K, Xia N, Li J, Yang C, Gao H, Yang Y (2020) NMR-based metabolomics characterizes metabolic changes in different brain regions of streptozotocin-induced diabetic mice with cognitive decline. Metab Brain Dis 35 (7):1165-1173

35. Song L, Zhu Y, Wang H, Belov AA, Niu J, Shi L, Xie Y, Ye C, Li X, Huang Z (2014) A solid-phase PEGylation strategy for protein therapeutics using a potent FGF21 analog. Biomaterials 35 (19):5206-5215

36. Zhao Q, Matsumoto K, Tsuneyama K, Tanaka K, Li F, Shibahara N, Miyata T, Yokozawa T (2011) Diabetes-induced central cholinergic neuronal loss and cognitive deficit are attenuated by tacrine and a Chinese herbal prescription, kangen-karyu: elucidation in type 2 diabetes $\mathrm{db} / \mathrm{db}$ mice. J Pharmacol Sci 117 (4):230-242

37. Morris R (1984) Developments of a water-maze procedure for studying spatial learning in the rat. J Neurosci Methods 11 (1):47-60

38. Hu W, Cheng X, Ye X, Zhao L, Huang Y, Zhu H, Yan Z, Wang X, Bai G, Gao H (2014) Ex vivo 1 H nuclear magnetic resonance spectroscopy reveals systematic alterations in cerebral metabolites as the key pathogenetic mechanism of bilirubin encephalopathy. Mol Brain 7 (1):87

39. Gao HC, Zhu H, Song CY, Lin L, Xiang Y, Yan ZH, Bai GH, Ye FQ, Li XK (2013) Metabolic changes detected by ex vivo high resolution $1 \mathrm{H}$ NMR spectroscopy in the striatum of 6-OHDA-induced Parkinson's rat. Mol Neurobiol 47 (1):123-130

40. Guan M, Xie L, Diao C, Wang N, Hu W, Zheng Y, Jin L, Yan Z, Gao H (2013) Systemic perturbations of key metabolites in diabetic rats during the evolution of diabetes studied by urine metabonomics. PLoS One 8 (4):e60409

41. Zhao L, Zhang H, Yang Y, Zheng Y, Dong M, Wang Y, Bai G, Ye X, Yan Z, Gao H (2014) Serum metabonomic analysis of protective effects of Curcuma aromatica oil on renal fibrosis rats. PLoS One 9 (9):e108678

42. Westerhuis JA, van Velzen EJ, Hoefsloot HC, Smilde AK (2010) Multivariate paired data analysis: multilevel PLSDA versus OPLSDA. Metabolomics 6 (1):119-128

43. Cloarec O, Dumas ME, Trygg J, Craig A, Barton RH, Lindon JC, Nicholson JK, Holmes E (2005) Evaluation of the orthogonal projection on latent structure model limitations caused by chemical shift variability and improved visualization of biomarker changes in 1H NMR spectroscopic metabonomic studies. Anal Chem 77 (2):517-526

44. Krieg AF, Gorton S, Henry JB (1967) Effect of temperature on activity and lactate optima of LDH isoenzymes. Clin Chim Acta 17 (3):363-366 
45. Zhao Y, Ye S, Lin J, Liang F, Chen J, Hu J, Chen K, Fang Y, Chen X, Xiong Y, Lin L, Tan X (2021) NmFGF1-Regulated Glucolipid Metabolism and Angiogenesis Improves Functional Recovery in a Mouse Model of Diabetic Stroke and Acts via the AMPK Signaling Pathway. Front Pharmacol $12: 680351$

46. Sun Y, Wang Y, Chen ST, Chen YJ, Shen J, Yao WB, Gao XD, Chen S (2020) Modulation of the Astrocyte-Neuron Lactate Shuttle System contributes to Neuroprotective action of Fibroblast Growth Factor 21. Theranostics 10 (18):8430-8445

47. Chen YJ, Mahieu NG, Huang X, Singh M, Crawford PA, Johnson SL, Gross RW, Schaefer J, Patti GJ (2016) Lactate metabolism is associated with mammalian mitochondria. Nat Chem Biol 12 (11):937943

48. Pierre K, Pellerin L (2005) Monocarboxylate transporters in the central nervous system: distribution, regulation and function. J Neurochem 94 (1):1-14

49. Rafiki A, Boulland JL, Halestrap AP, Ottersen OP, Bergersen L (2003) Highly differential expression of the monocarboxylate transporters MCT2 and MCT4 in the developing rat brain. Neuroscience 122 (3):677-688

50. Pierre K, Magistretti PJ, Pellerin L (2002) MCT2 is a major neuronal monocarboxylate transporter in the adult mouse brain. J Cereb Blood Flow Metab 22 (5):586-595

51. Chenal J, Pierre K, Pellerin L (2008) Insulin and IGF-1 enhance the expression of the neuronal monocarboxylate transporter MCT2 by translational activation via stimulation of the phosphoinositide 3-kinase-Akt-mammalian target of rapamycin pathway. Eur J Neurosci 27 (1):53-65

52. Robinet C, Pellerin L (2010) Brain-derived neurotrophic factor enhances the expression of the monocarboxylate transporter 2 through translational activation in mouse cultured cortical neurons. $J$ Cereb Blood Flow Metab 30 (2):286-298

53. Ying L, Li N, He Z, Zeng X, Nan Y, Chen J, Miao P, Ying Y, Lin W, Zhao X, Lu L, Chen M, Cen W, Guo T, Li $X$, Huang Z, Wang Y (2019) Fibroblast growth factor 21 Ameliorates diabetes-induced endothelial dysfunction in mouse aorta via activation of the CaMKK2/AMPKalpha signaling pathway. Cell Death Dis $10(9): 665$

54. Hsuchou H, Pan W, Kastin AJ (2007) The fasting polypeptide FGF21 can enter brain from blood. Peptides 28 (12):2382-2386

55. Alle H, Roth A, Geiger JR (2009) Energy-efficient action potentials in hippocampal mossy fibers. Science 325 (5946):1405-1408

56. Belanger M, Allaman I, Magistretti PJ (2011) Brain energy metabolism: focus on astrocyte-neuron metabolic cooperation. Cell Metab 14 (6):724-738

57. Fiebig C, Keiner S, Ebert B, Schaffner I, Jagasia R, Lie DC, Beckervordersandforth R (2019) Mitochondrial Dysfunction in Astrocytes Impairs the Generation of Reactive Astrocytes and Enhances Neuronal Cell Death in the Cortex Upon Photothrombotic Lesion. Front Mol Neurosci 12:40

58. Williams HC, Farmer BC, Piron MA, Walsh AE, Bruntz RC, Gentry MS, Sun RC, Johnson LA (2020) APOE alters glucose flux through central carbon pathways in astrocytes. Neurobiol Dis 136:104742 
59. Harris RA, Tindale L, Lone A, Singh O, Macauley SL, Stanley M, Holtzman DM, Bartha R, Cumming RC (2016) Aerobic Glycolysis in the Frontal Cortex Correlates with Memory Performance in Wild-Type Mice But Not the APP/PS1 Mouse Model of Cerebral Amyloidosis. J Neurosci 36 (6):1871-1878

60. Yao J, Rettberg JR, Klosinski LP, Cadenas E, Brinton RD (2011) Shift in brain metabolism in late onset Alzheimer's disease: implications for biomarkers and therapeutic interventions. Mol Aspects Med 32 (4-6):247-257

61. Zheng H, Lin Q, Wang D, Xu P, Zhao L, Hu W, Bai G, Yan Z, Gao H (2017) NMR-based metabolomics reveals brain region-specific metabolic alterations in streptozotocin-induced diabetic rats with cognitive dysfunction. Metab Brain Dis

62. Wang D, Zhao L, Zheng H, Dong M, Pan L, Zhang X, Zhang H, Gao H (2018) Time-Dependent Lactate Production and Amino Acid Utilization in Cultured Astrocytes Under High Glucose Exposure. Mol Neurobiol 55 (2):1112-1122

63. Zhao L, Dong M, Wang D, Ren M, Zheng Y, Zheng H, Li C, Gao H (2018) Characteristic Metabolic Alterations Identified in Primary Neurons Under High Glucose Exposure. Front Cell Neurosci 12:207

64. Pellerin L, Magistretti PJ (1994) Glutamate uptake into astrocytes stimulates aerobic glycolysis: a mechanism coupling neuronal activity to glucose utilization. Proc Natl Acad Sci U S A 91 (22):1062510629

65. Nagase M, Takahashi Y, Watabe AM, Kubo Y, Kato F (2014) On-site energy supply at synapses through monocarboxylate transporters maintains excitatory synaptic transmission. J Neurosci 34 (7):2605-2617

66. Angamo EA, Rosner J, Liotta A, Kovacs R, Heinemann U (2016) A neuronal lactate uptake inhibitor slows recovery of extracellular ion concentration changes in the hippocampal CA3 region by affecting energy metabolism. J Neurophysiol 116 (5):2420-2430

67. Margineanu MB, Mahmood H, Fiumelli H, Magistretti PJ (2018) L-Lactate Regulates the Expression of Synaptic Plasticity and Neuroprotection Genes in Cortical Neurons: A Transcriptome Analysis. Front Mol Neurosci 11:375

68. Magistretti PJ, Allaman I (2018) Lactate in the brain: from metabolic end-product to signalling molecule. Nat Rev Neurosci 19 (4):235-249

69. Mosienko V, Teschemacher AG, Kasparov S (2015) Is L-lactate a novel signaling molecule in the brain? J Cereb Blood Flow Metab 35 (7):1069-1075

70. Suzuki A, Stern SA, Bozdagi O, Huntley GW, Walker RH, Magistretti PJ, Alberini CM (2011) Astrocyteneuron lactate transport is required for long-term memory formation. Cell 144 (5):810-823

71. Brooks GA (2009) Cell-cell and intracellular lactate shuttles. J Physiol 587 (Pt 23):5591-5600

72. Yang J, Ruchti E, Petit JM, Jourdain P, Grenningloh G, Allaman I, Magistretti PJ (2014) Lactate promotes plasticity gene expression by potentiating NMDA signaling in neurons. Proc Natl Acad Sci U S A 111 (33):12228-12233

73. Makela J, Tselykh TV, Maiorana F, Eriksson O, Do HT, Mudo G, Korhonen LT, Belluardo N, Lindholm D (2014) Fibroblast growth factor-21 enhances mitochondrial functions and increases the activity of 
PGC-1 alpha in human dopaminergic neurons via Sirtuin-1. Springerplus 3:2

74. Sa-Nguanmoo P, Tanajak P, Kerdphoo S, Satjaritanun P, Wang X, Liang G, Li X, Jiang C, Pratchayasakul W, Chattipakorn N, Chattipakorn SC (2016) FGF21 improves cognition by restored synaptic plasticity, dendritic spine density, brain mitochondrial function and cell apoptosis in obeseinsulin resistant male rats. Horm Behav 85:86-95

75. Sarruf DA, Thaler JP, Morton GJ, German J, Fischer JD, Ogimoto K, Schwartz MW (2010) Fibroblast growth factor 21 action in the brain increases energy expenditure and insulin sensitivity in obese rats. Diabetes 59 (7):1817-1824

76. Wang Q, Yuan J, Yu Z, Lin L, Jiang Y, Cao Z, Zhuang P, Whalen MJ, Song B, Wang XJ, Li X, Lo EH, Xu Y, Wang X (2018) FGF21 Attenuates High-Fat Diet-Induced Cognitive Impairment via Metabolic Regulation and Anti-inflammation of Obese Mice. Mol Neurobiol 55 (6):4702-4717

77. Datta S, Chakrabarti N (2018) Age related rise in lactate and its correlation with lactate dehydrogenase (LDH) status in post-mitochondrial fractions isolated from different regions of brain in mice. Neurochem Int 118:23-33

78. Ross JM, Oberg J, Brene S, Coppotelli G, Terzioglu M, Pernold K, Goiny M, Sitnikov R, Kehr J, Trifunovic A, Larsson NG, Hoffer BJ, Olson L (2010) High brain lactate is a hallmark of aging and caused by a shift in the lactate dehydrogenase A/B ratio. Proc Natl Acad Sci U S A 107 (46):2008720092

79. Fan J, Hitosugi T, Chung TW, Xie J, Ge Q, Gu TL, Polakiewicz RD, Chen GZ, Boggon TJ, Lonial S, Khuri FR, Kang S, Chen J (2011) Tyrosine phosphorylation of lactate dehydrogenase A is important for $\mathrm{NADH} / \mathrm{NAD}(+)$ redox homeostasis in cancer cells. Mol Cell Biol 31 (24):4938-4950

80. Liu J, Chen G, Liu Z, Liu S, Cai Z, You P, Ke Y, Lai L, Huang Y, Gao H, Zhao L, Pelicano H, Huang P, McKeehan WL, Wu CL, Wang C, Zhong W, Wang F (2018) Aberrant FGFR Tyrosine Kinase Signaling Enhances the Warburg Effect by Reprogramming LDH Isoform Expression and Activity in Prostate Cancer. Cancer Res 78 (16):4459-4470

81. Shima T, Jesmin S, Matsui T, Soya M, Soya H (2018) Differential effects of type 2 diabetes on brain glycometabolism in rats: focus on glycogen and monocarboxylate transporter 2. J Physiol Sci 68 (1):69-75

82. Lu W, Huang J, Sun S, Huang S, Gan S, Xu J, Yang M, Xu S, Jiang X (2015) Changes in lactate content and monocarboxylate transporter 2 expression in Abeta(2)(5)(-)(3)(5)-treated rat model of Alzheimer's disease. Neurol Sci 36 (6):871-876

83. Netzahualcoyotzi C, Pellerin L (2020) Neuronal and astroglial monocarboxylate transporters play key but distinct roles in hippocampus-dependent learning and memory formation. Prog Neurobiol 194:101888

84. Do HT, Tselykh TV, Makela J, Ho TH, Olkkonen VM, Bornhauser BC, Korhonen L, Zelcer N, Lindholm D (2012) Fibroblast growth factor-21 (FGF21) regulates low-density lipoprotein receptor (LDLR) levels in cells via the E3-ubiquitin ligase Mylip/Idol and the Canopy2 (Cnpy2)/Mylip-interacting saposin-like protein (Msap). J Biol Chem 287 (16):12602-12611 
85. Kharitonenkov A, Shiyanova TL, Koester A, Ford AM, Micanovic R, Galbreath EJ, Sandusky GE, Hammond LJ, Moyers JS, Owens RA, Gromada J, Brozinick JT, Hawkins ED, Wroblewski VJ, Li DS, Mehrbod F, Jaskunas SR, Shanafelt AB (2005) FGF-21 as a novel metabolic regulator. J Clin Invest 115 (6):1627-1635

86. Geng L, Lam KSL, Xu A (2020) The therapeutic potential of FGF21 in metabolic diseases: from bench to clinic. Nat Rev Endocrinol 16 (11):654-667

87. Pierre K, Chatton JY, Parent A, Repond C, Gardoni F, Di Luca M, Pellerin L (2009) Linking supply to demand: the neuronal monocarboxylate transporter MCT2 and the alpha-amino-3-hydroxyl-5-methyl4-isoxazole-propionic acid receptor GluR2/3 subunit are associated in a common trafficking process. Eur J Neurosci 29 (10):1951-1963

88. Robinet C, Pellerin L (2011) Brain-derived neurotrophic factor enhances the hippocampal expression of key postsynaptic proteins in vivo including the monocarboxylate transporter MCT2. Neuroscience 192:155-163

89. Tomiyama K, Maeda R, Urakawa I, Yamazaki Y, Tanaka T, Ito S, Nabeshima Y, Tomita T, Odori S, Hosoda K, Nakao K, Imura A, Nabeshima Y (2010) Relevant use of Klotho in FGF19 subfamily signaling system in vivo. Proc Natl Acad Sci U S A 107 (4):1666-1671

\section{Figures}
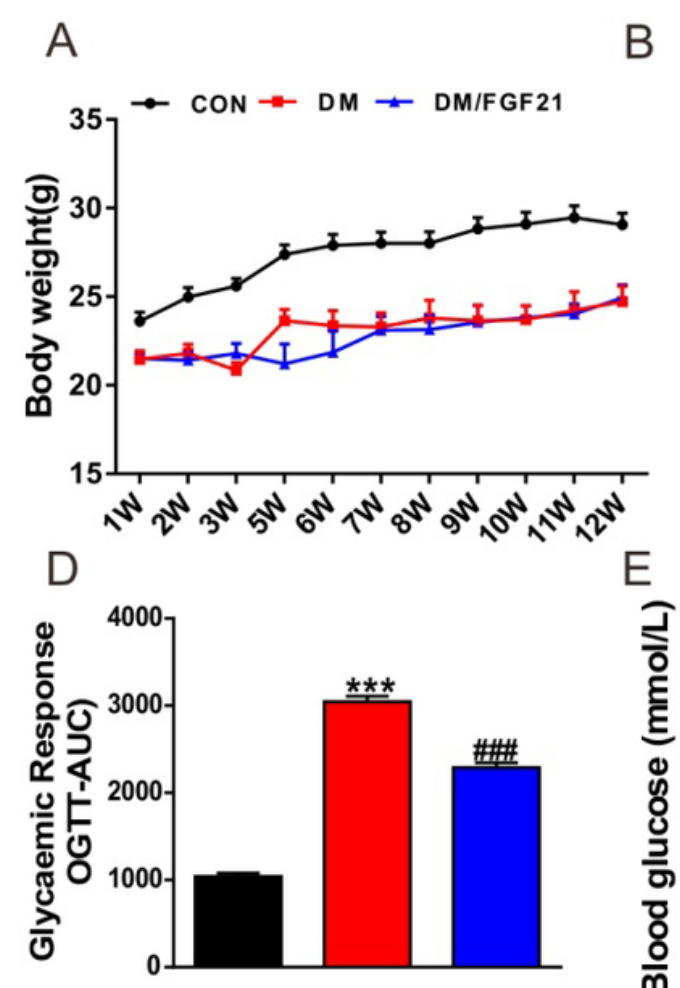

$B$

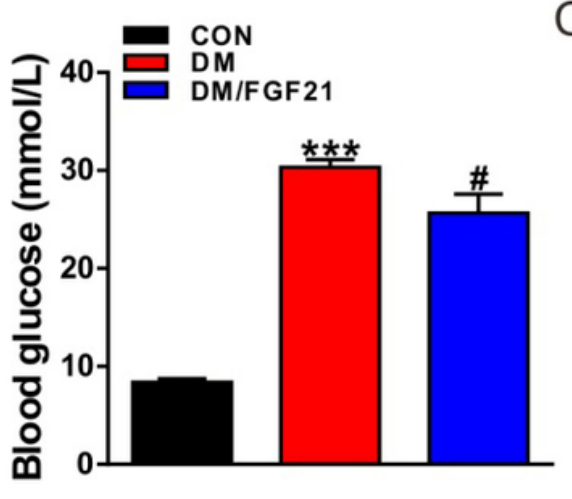

\section{$\mathrm{E}$}

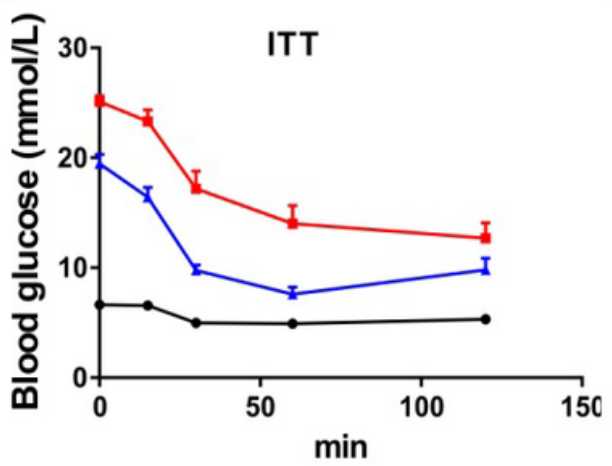

$\mathrm{C}$

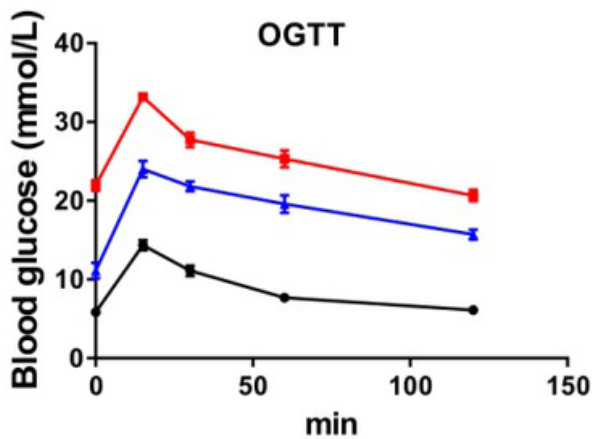

$\mathrm{F}$

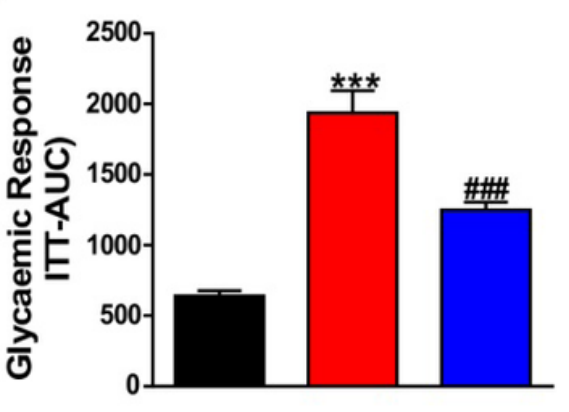

Figure 1 
Effects of FGF21 on blood glucose and body weight levels in diabetic mice. (A) Body weight levels. (B) Blood glucose levels. (C-D) Oral glucose tolerance test and area under the curve (AUC). (E-F) Insulin tolerance test and AUC. $\mathrm{n}=9 .{ }^{*} p<0.05,{ }^{* \star} p<0.01,{ }^{* \star *} p<0.001$ versus CON group; ${ }^{\#} p<0.05,{ }^{\# \#} p<0.01$, $\# \# p<0.001$ versus $\mathrm{DM}$ group.

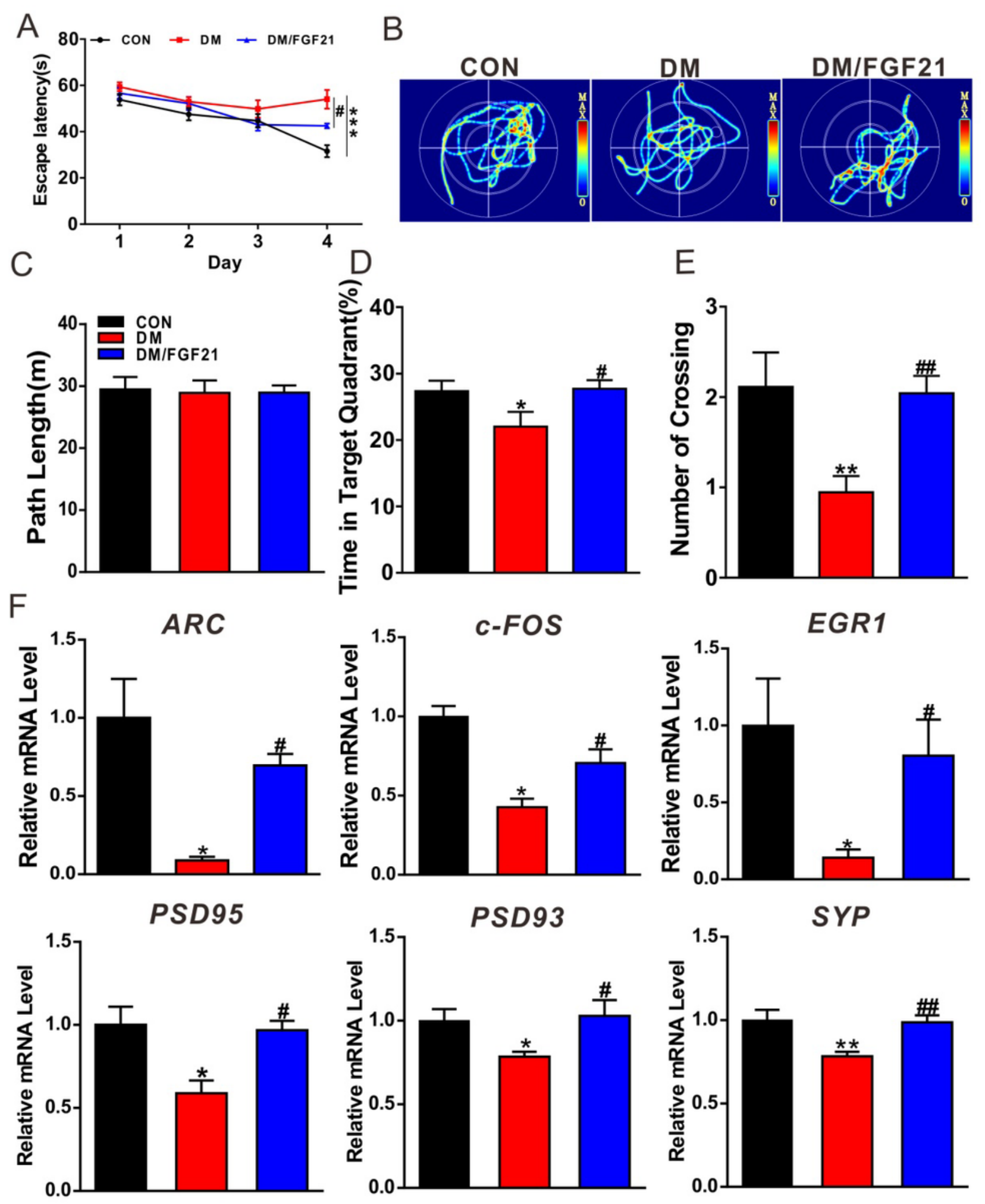

Figure 2 
FGF21 ameliorates learning and memory impairments in diabetic mice. (A) In hidden platform tests, the mean escape latency was compared in control, diabetic and FGF21 groups. (B) Representative swim track of the mice. (C) Mean path length in probe trail . (D-E) Time percent in target quadrant and number of crossing in probe trial of MWM on day 5. $n=6-9$. (F) RT-PCR determination of mRNA levels of activityregulated cytoskeleton-associated protein (Arc), c-Fos, early growth response-1 (EGR-1), presynaptic (SYP) and postsynaptic proteins (PSD-93 and PSD-95)in the hippocampal extracts of the mice. $\mathrm{n}=4-6$. ${ }^{*} p<0.05,{ }^{* \star} p<0.01,{ }^{* \star *} p<0.001$ versus CON group; ${ }^{\#} p<0.05,{ }^{\# \#} p<0.01,{ }^{\# \# \#} p<0.001$ versus DM group.
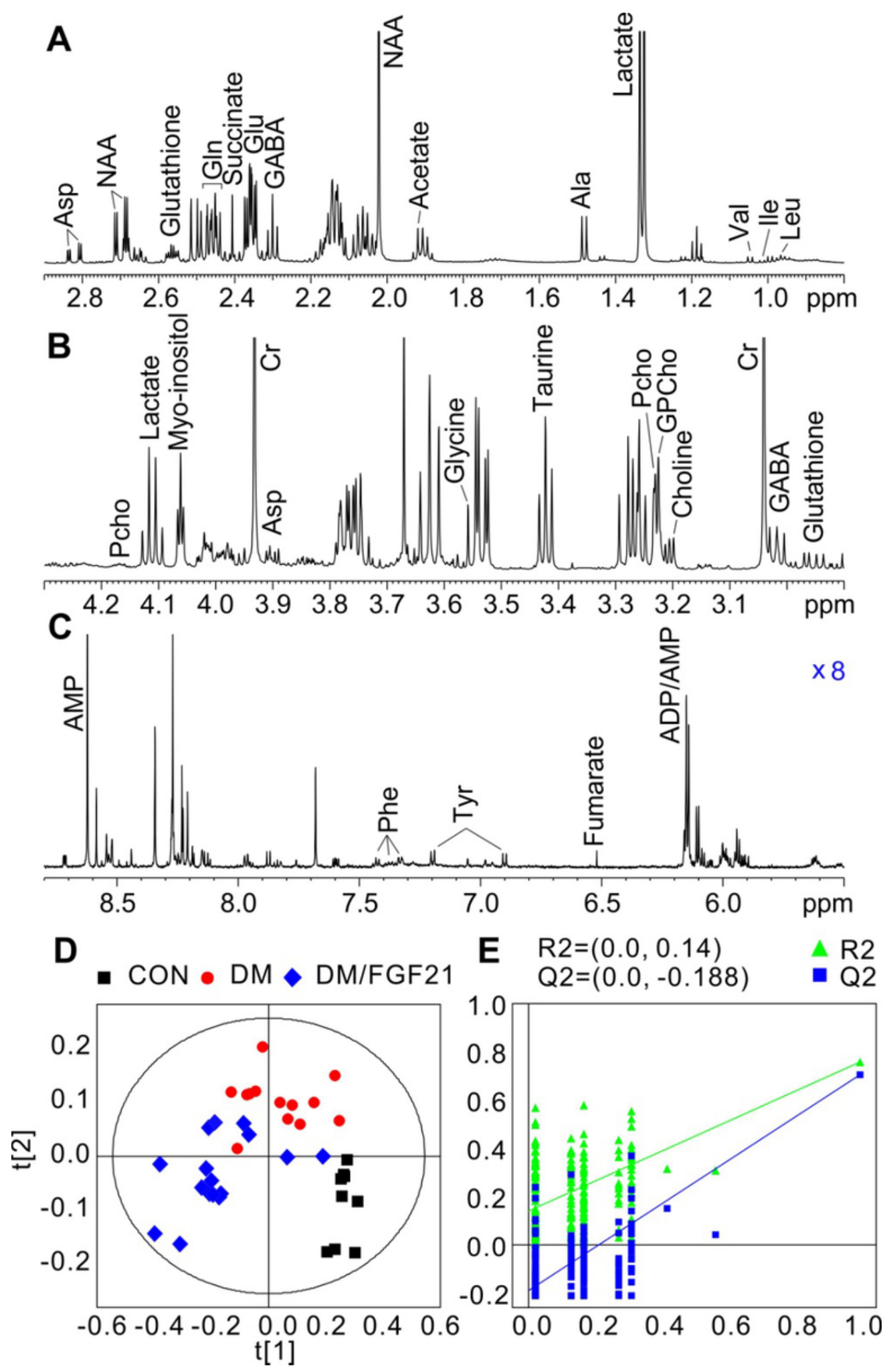


\section{Figure 3}

Representative ${ }^{1} \mathrm{H}$ NMR spectra and multivariate pattern recognition analysis of the hippocampus extracts of the mice. (A-C) Different ${ }^{1} \mathrm{H}$ NMR spectral regions from one control mice. (D-E) PLS-DA scores plot and cross-validated plot for the models discriminating the CON, DM, and DM/FGF21 groups. $n=8$ 15. Keys: Leu, leucine; Ile, isoleucine; Val, Valine; Ala, alanine; NAA, N-acetyl-aspartate; GABA, Yaminobutyric acid; Glu, glutamate; Gln, glutamine; Asp, aspartate; $\mathrm{Cr}$, creatine; GPCho, glycerophosphocholine; PCho, phosphocholine; Tyr, tyrosine; Phe, phenylalanine.
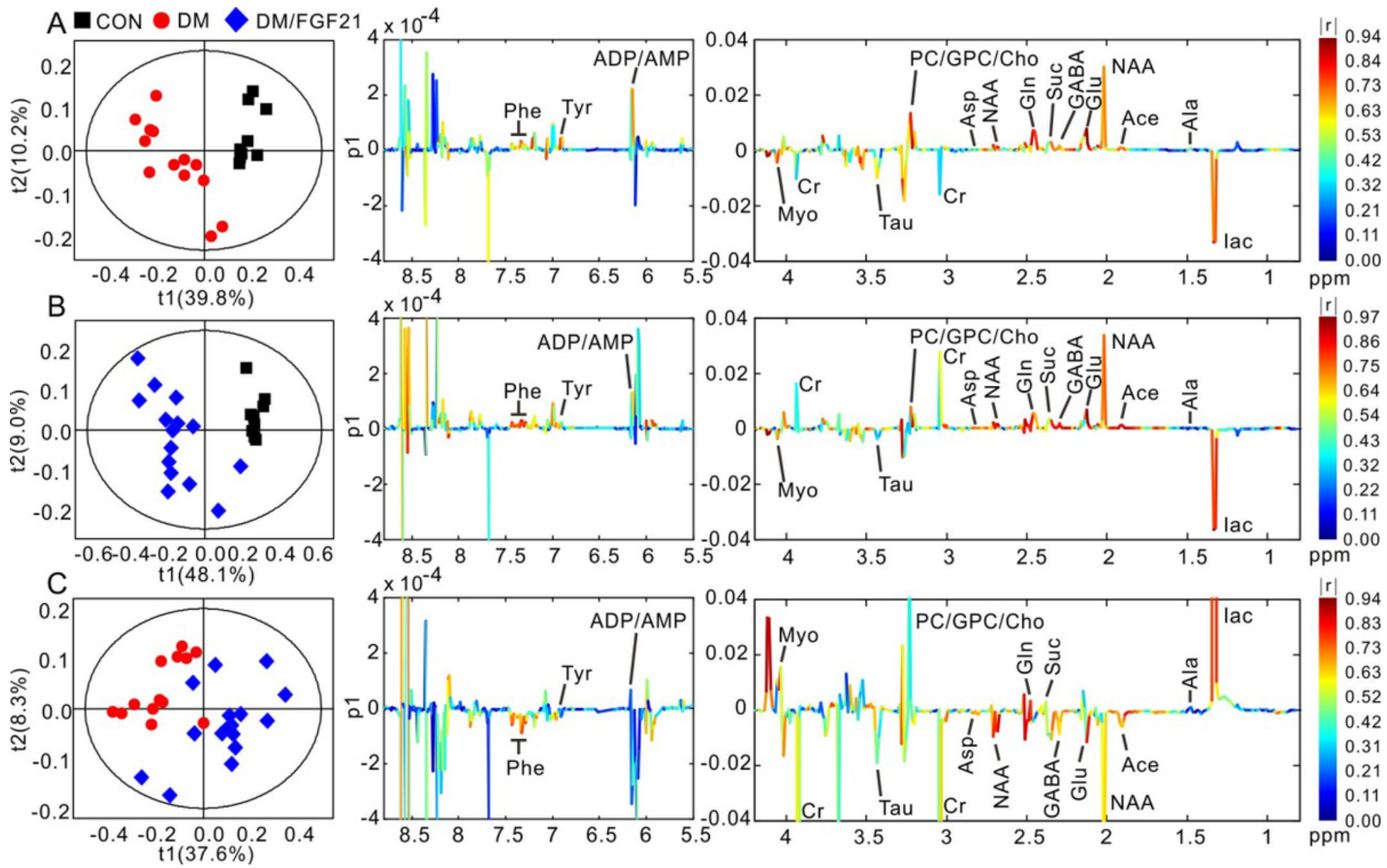

\section{Figure 4}

PLS-DA scores and coefficient-coded loading plots of ${ }^{1} \mathrm{H}$ NMR spectra of hippocampus extracts of the mice. (A) CON versus DM groups. (B) CON versus DM/FGF21 groups. (C) DM versus DM/FGF21 groups. The loading plot (right) corresponds to $\mathrm{t} 1$ in the corresponding score plot (left). Peaks in the positive direction of the loading plots indicate increased metabolites in the group which located in the same positive direction of the corresponding score plot. The color of the loading plot which represent value of $|r|$, can be used to identify the variables to class separation. The corresponding model parameters are listed in Table S2. Metabolite assignments are the same as in Figure 3. 

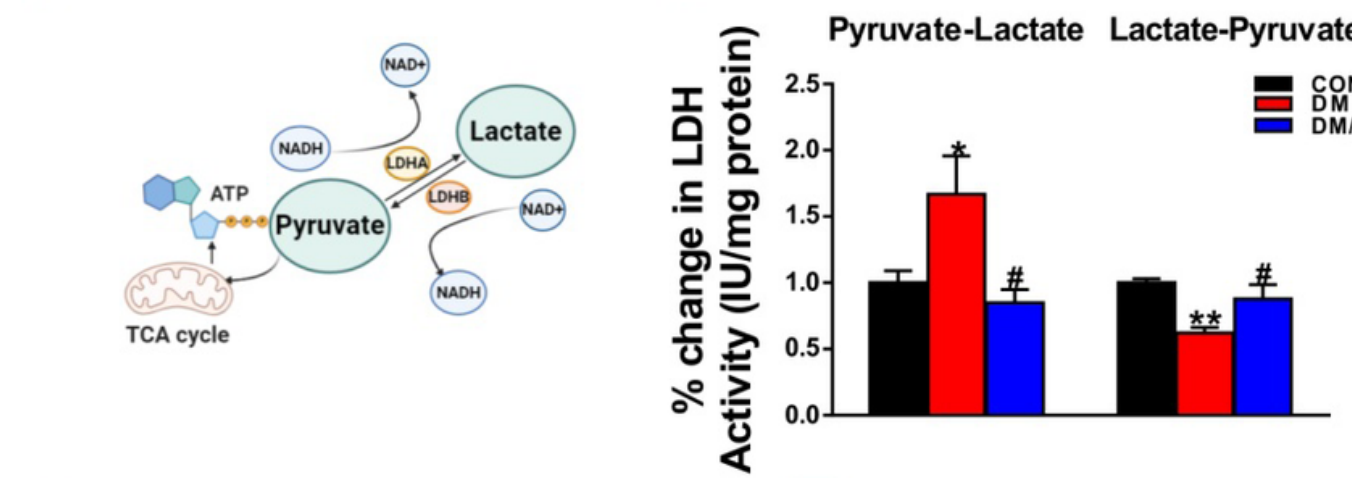

C

D
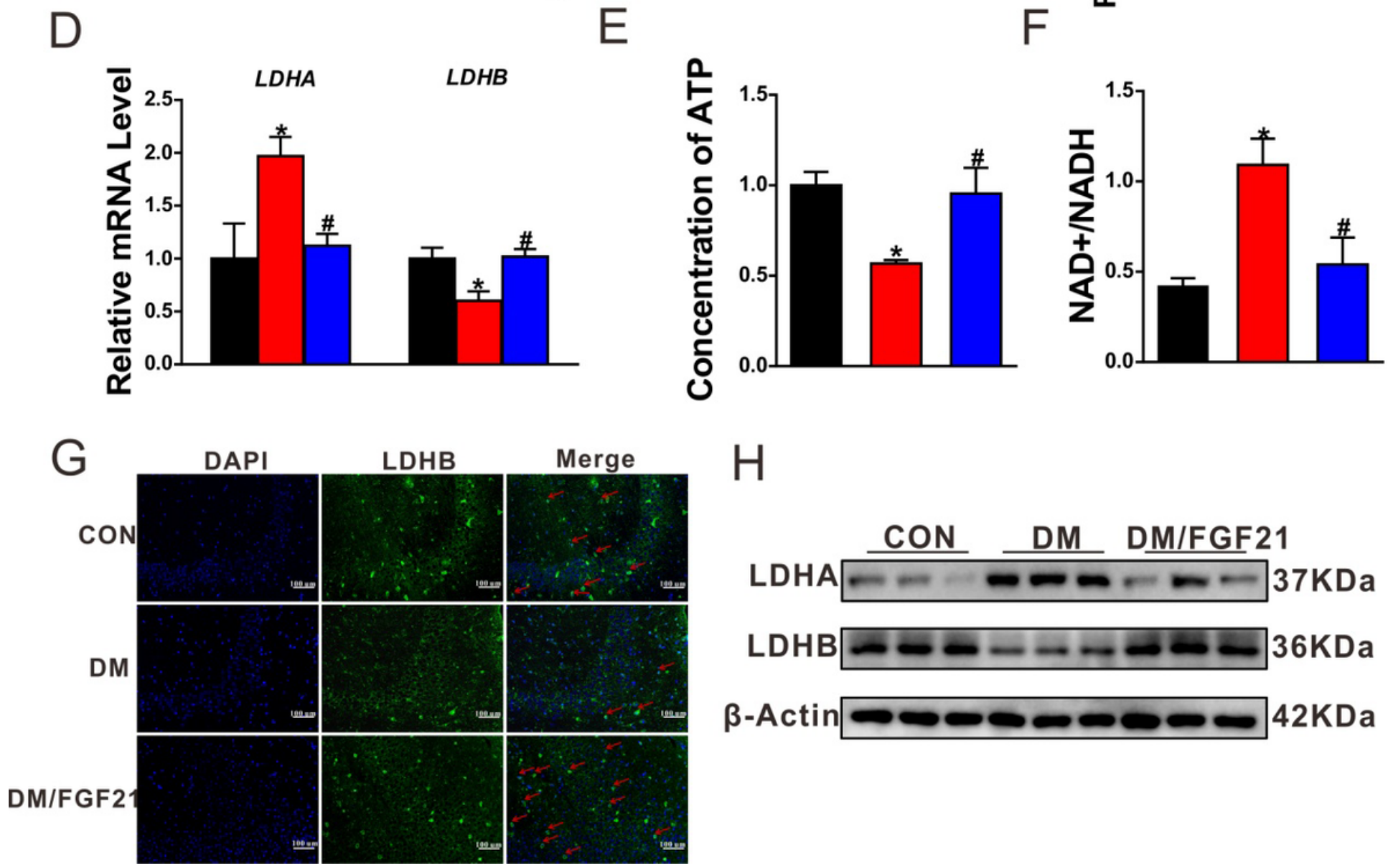

H

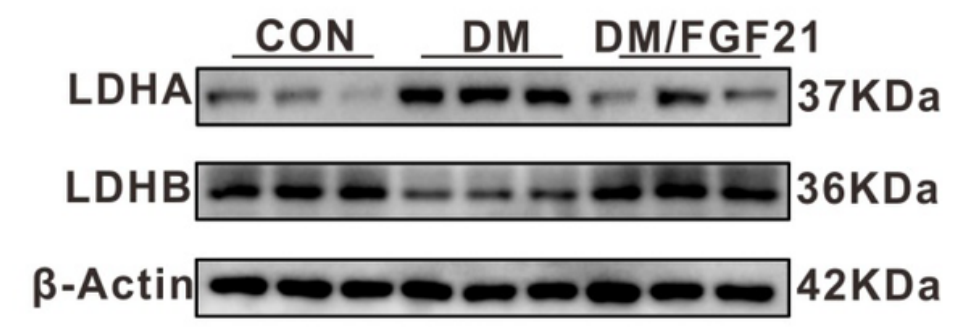

Figure 5

FGF21 promotes lactate usage in the diabetic mice by remodeling glycolytic process. (A) Schematic diagram of glycolysis. (B) Quantification of LDH enzymatic activity from both pyruvate and lactate sides of the reaction suggests a metabolic shift to lactate production in diabetic mice, while FGF21 treatment can restore the trend. (C) The P:L ratio is a simplified reflection of the LDH activity (IU/mg protein) during interconversion of pyruvate and lactate. (D) RT-PCR data of $L D H-A$ and $L D H-B$ mRNA levels. (E-F) ATP and $\mathrm{NAD}^{+} / \mathrm{NADH}$ levels. (G) Immunofluorescence of LDH-B expressions in the hippocampal CA3 regions (scale bar, $100 \mu \mathrm{m}$ ). (H) Western blot of LDH-A and LDH-B protein expressions. $\mathrm{n}=4-6 .{ }^{*} p<0.05,{ }^{* *} p<$ $0.01,{ }^{* \star *} p<0.001$ versus CON group; ${ }^{\#} p<0.05,{ }^{\# \#} p<0.01,{ }^{\# \# \#} p<0.001$ versus DM group. 
A

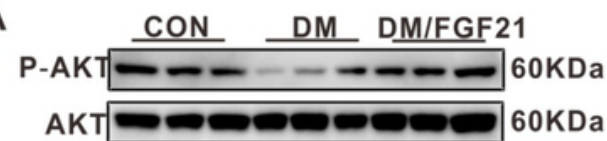

P-mTOR OOD- 289KDa mTOR DOCODED 289Ka P-P70 $=--\cdots$ KDa P70 МСT1 - $-43 \mathrm{KDa}$ МСт2 $-(-\cdots-\cdots 45 \mathrm{KDa}$ MCT4 $--0-25 \mathrm{KDa}$ $\beta$-Actin $=0$

D

$\mathrm{ACM}-+++$

FGF21 - $\quad-\quad+\quad+$

LY $294002 \quad-\quad$ - $\quad$ -

$\mathrm{P}-\mathrm{PI} 3 \mathrm{~K} \longrightarrow-\longrightarrow 110 \mathrm{KDa}$

$\mathrm{PI} 3 \mathrm{~K} \longrightarrow-\longrightarrow$ 110KDa

MCT2 $--\longrightarrow 45 \mathrm{KDa}$

GAPDH $\longrightarrow 38 \mathrm{KDa}$

$\mathrm{F}$

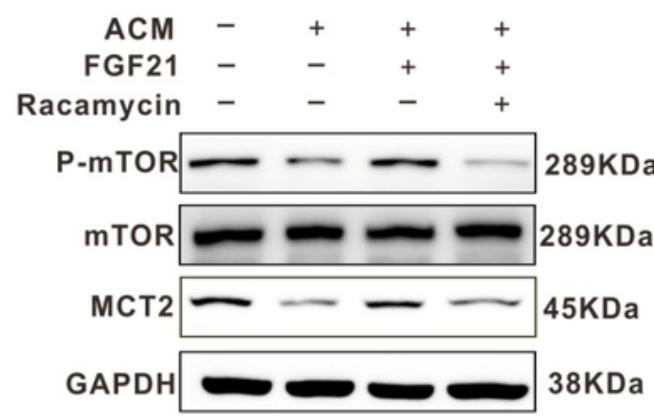

$\mathrm{H}$

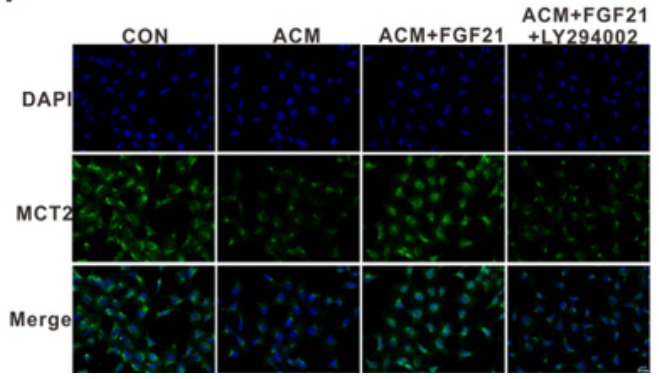

B
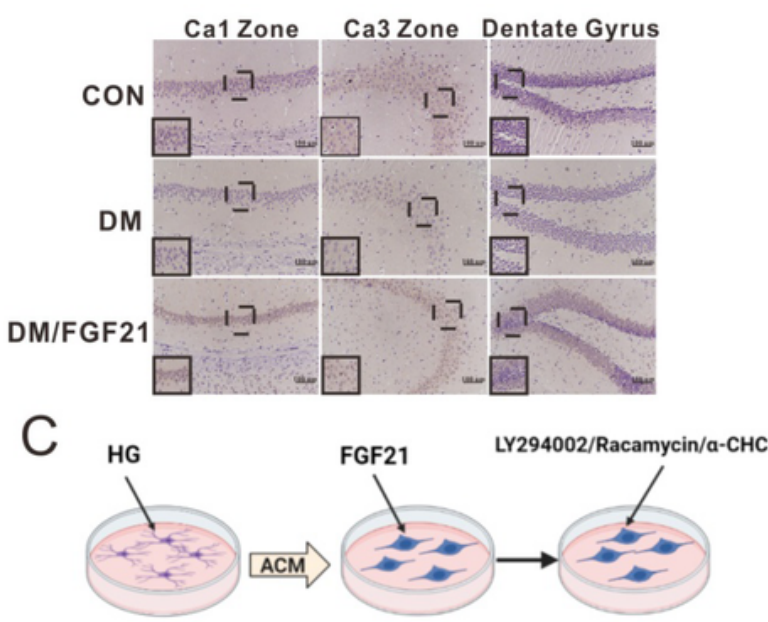

E

- SH-SY5Y neuron

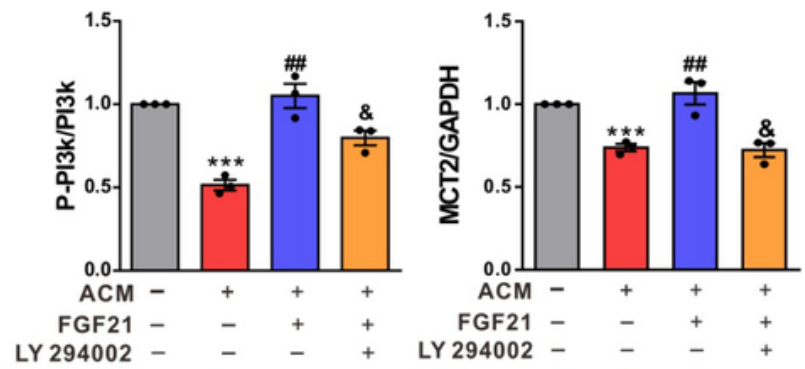

G
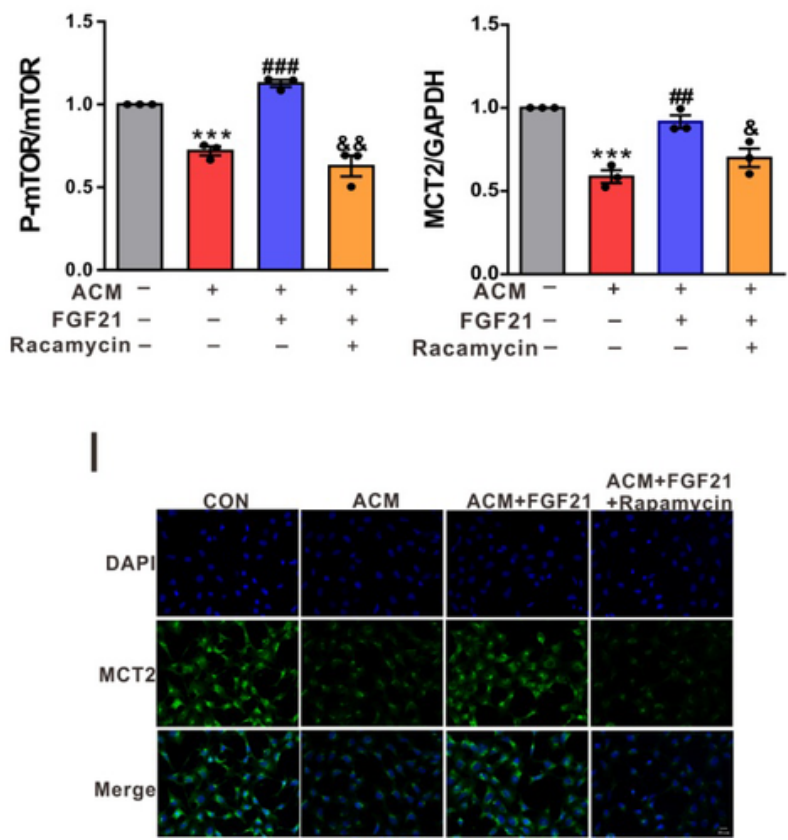

\section{Figure 6}

FGF21 promotes lactate uptake via the PI3K-dependent MCT2 pathway. (A) Western blot determination of MCT1, 2, 4 expressions and PI3K signal pathway. (B) Immunohistochemistry of MCT2 expressions in the hippocampal CA1, CA3 and DG regions (scale bar, $100 \mu \mathrm{m}$ ). (C) Cell conditional culture process. All SHSY5Y cell was treated with astrocyte conditioned media (ACM). (D-E) Western blot data of MCT2 expressions after PI3K inhibitor treatment (LY294002, $10 \mu \mathrm{M}$ ) in SH-SY5Y cells. (F-G) Western blot data of 
MCT2 expressions after mTOR inhibitor treatment (Rapamycin, $20 \mathrm{ng} / \mathrm{mL}$ ) in SH-SY5Y cell. $(\mathrm{H}-\mathrm{I})$ Immunofluorescence of MCT2 expressions after PI3K and mTOR inhibitors treatment in SH-SY5Y cells (scale bar, $20 \mu \mathrm{m}$ ). $\mathrm{n}=3 .{ }^{*} \mathrm{p}<0.05,{ }^{\star \star} \mathrm{p}<0.01,{ }^{\star \star *} \mathrm{p}<0.001$ versus CON group. ${ }^{\#} \mathrm{p}<0.05,{ }^{\# \#} \mathrm{p}<0.01,{ }^{\# \#} \mathrm{p}<$ 0.001 versus $A C M$ group. ${ }^{\&} p<0.05,{ }^{\&} p<0.01,{ }^{\& \& \&} p<0.001$ versus $A C M+F G F 21$ group.

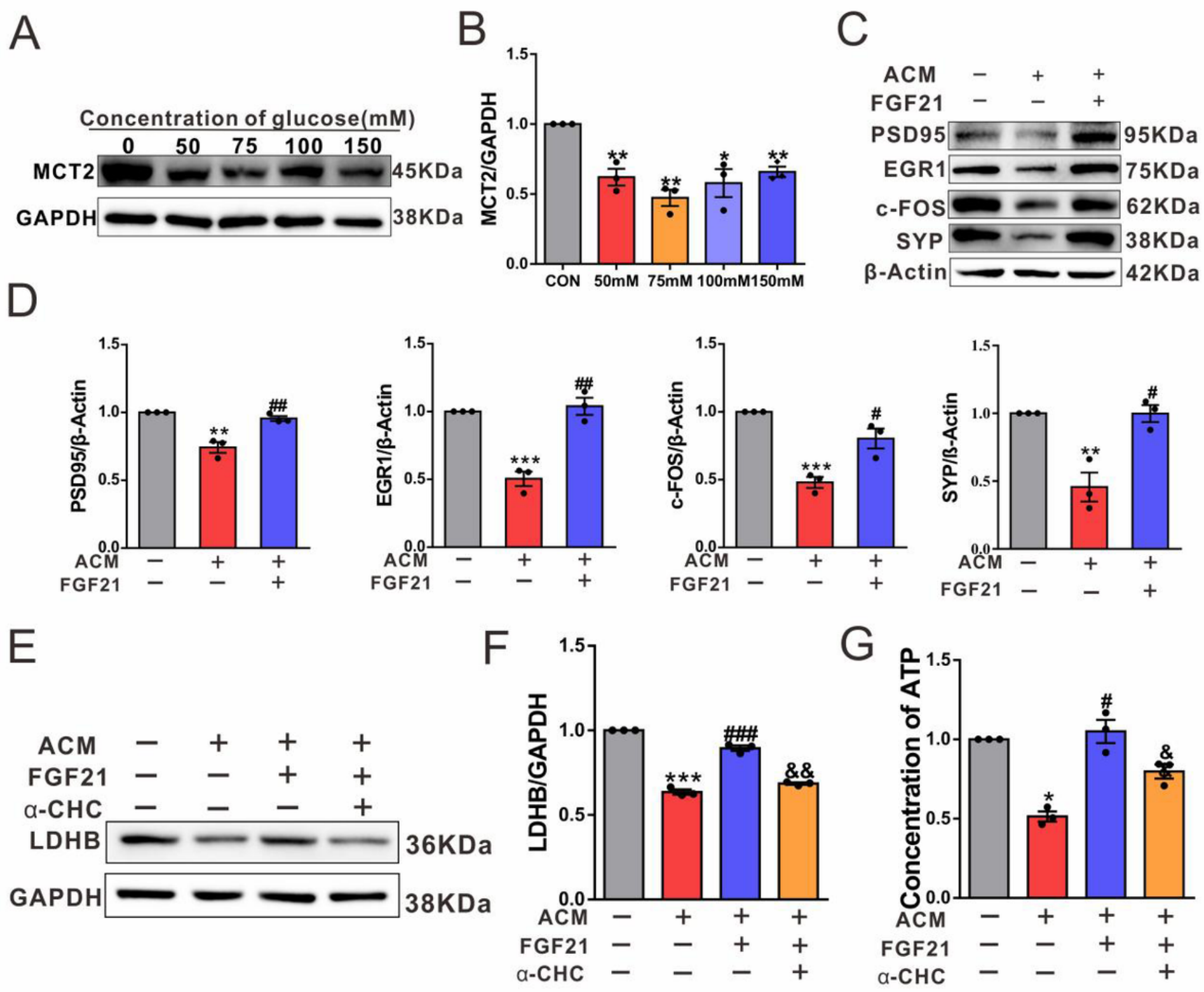

Figure 7

FGF21 promotes synaptic proteins, immediate early genes via the PI3K-dependent MCT2 pathway in SHSY5Y cells. (A-B) Protein levels of MCT2 in astrocyte-conditioned media (ACM) treated with different glucose concentrations in SH-SY5Y cells. (C-D) Western blot determination of protein levels of PSD-95, EGR-1, c-Fos and SYP in the SH-SY5Y cells. (E-F) Western blot determination of LDHB expressions after MCT2 inhibitor (a-Cyano-4-hydroxycinnamic acid, a-CHC, $2.5 \mathrm{mM}$ ) treatment. (G) ATP levels. $n=3,{ }^{*} \mathrm{p}<$ 
$0.05,{ }^{* *} \mathrm{p}<0.01,{ }^{* \star *} \mathrm{p}<0.001$ versus CON group. ${ }^{\#} \mathrm{p}<0.05,{ }^{\# \#} \mathrm{p}<0.01,{ }^{\# \# \#} \mathrm{p}<0.001$ versus ACM group. ${ }^{\circledR} \mathrm{p}<$ $0.05,{ }^{\& \&} p<0.01, \& \& p<0.001$ versus ACM + FGF21 group.

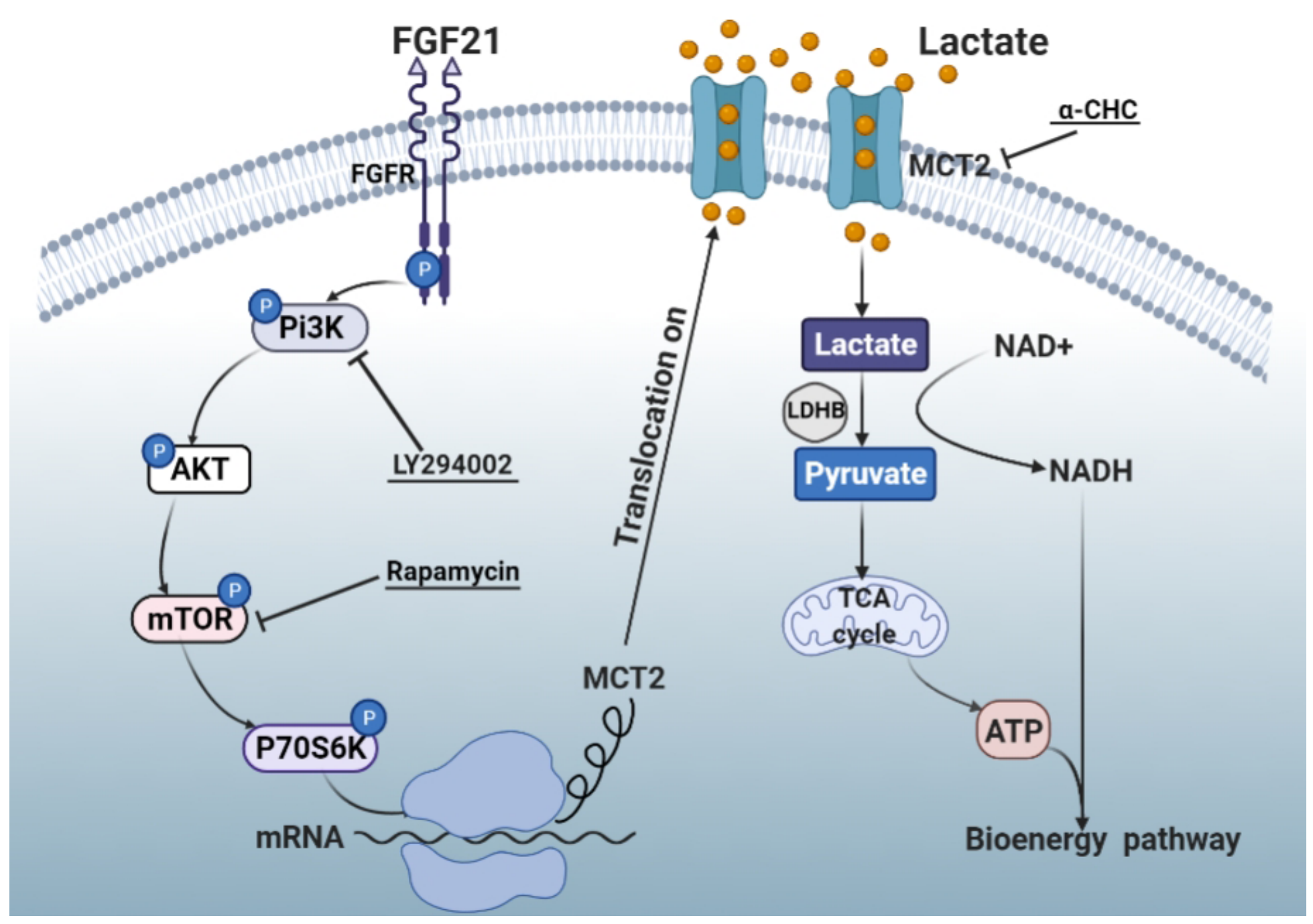

\section{Figure 8}

Schematic diagram of FGF21-mediated enhancement of bioenergy production in the neurons of mice. The PI3K/Akt/mTOR signal pathway dependent MCT2 expressions are reduced by hyperglycemic insults. FGF21 binds to FGFR to potentiate PI3K/Akt/mTOR activities, as well as MCT2 expressions in protein levels. On the one hand, MCT2-mediated lactate uptake may contribute to the glycolytic shifts (pyruvate to lactate direction), followed by NADH, and ATP production, which lead to bioenergy production and learning and memory restoration. Keys: LDH, lactate dehydrogenase; MCT2, monocarboxylate transporter 2; FGF, fibroblast growth factor. (Created in BioRender.com)

\section{Supplementary Files}

This is a list of supplementary files associated with this preprint. Click to download.

- lactatesupplement20220126.docx 